\title{
Public Perception of Artificial Intelligence and Its Connections to the Sustainable Development Goals
}

\author{
Shin-Cheng Yeh ${ }^{1, *(\mathbb{D}}$, Ai-Wei Wu ${ }^{1}$, Hui-Ching Yu ${ }^{2}$, Homer $\mathrm{C} . \mathrm{Wu}^{3}$, Yi-Ping Kuo ${ }^{1}$ and Pei-Xuan Chen ${ }^{1}$ \\ 1 Graduate Institute of Environmental Education, National Taiwan Normal University, Taipei 11677, Taiwan; \\ awu@ntnu.edu.tw (A.-W.W.); 60846019s@ntnu.edu.tw (Y.-P.K.); 60846004s@ntnu.edu.tw (P.-X.C.) \\ 2 Department of Food \& Beverage Management, Cheng-Shiu University, Kaohsiung City 83347, Taiwan; \\ k0299@gcloud.csu.edu.tw \\ 3 Graduate Program of Sustainable Tourism \& Recreation Management, National Taichung University of \\ Education, Taichung 40359, Taiwan; hcwu@mail.ntcu.edu.tw \\ * Correspondence: scyeh@ntnu.edu.tw; Tel.: +886-2-77496563
}

Citation: Yeh, S.-C.; Wu, A.-W.; Yu, H.-C.; Wu, H.C.; Kuo, Y.-P.; Chen, P.-X. Public Perception of Artificial Intelligence and Its Connections to the Sustainable Development Goals. Sustainability 2021, 13, 9165. https:// doi.org/10.3390/su13169165

Academic Editor: Andrea Appolloni

Received: 2 July 2021

Accepted: 13 August 2021

Published: 16 August 2021

Publisher's Note: MDPI stays neutral with regard to jurisdictional claims in published maps and institutional affiliations.

Copyright: (c) 2021 by the authors. Licensee MDPI, Basel, Switzerland. This article is an open access article distributed under the terms and conditions of the Creative Commons Attribution (CC BY) license (https:// creativecommons.org/licenses/by/ $4.0 /)$.

\begin{abstract}
Artificial Intelligence (AI) will not just change our lives but bring about revolutionary transformation. AI can augment efficiencies of good and bad things and thus has been considered both an opportunity and risk for the sustainable development of humans. This study designed a survey to collect 1018 samples of educated people with access to the internet in Taiwan regarding their perceptions of $\mathrm{AI}$ and its connections to the Sustainable Development Goals (SDGs). The respondents showed high confidence in their AI knowledge. They had a very positive attitude toward AI but at the same time thought AI was risky. In general, people in Taiwan could be "rational optimists" regarding AI. We also examined how people think of the linkages between AI and the SDGs and found that SDG 4, SDG 9, and SDG 3 had the highest "synergy" and lowest rates of "trade-off". Significant differences for some key questions were also identified concerning the demographic variables such as gender, age, education, and college major. According to the data analysis, education played as the base to construct a sustainable AI-aided town with an embedded innovative circular economy and high-quality water and energy services, making the residents live healthier lives. The findings of this study can be referred to when the perceptions of AI and sustainability issues are of interest for an emerging high-tech economy such as Taiwan and other Asian countries.
\end{abstract}

Keywords: artificial intelligence; AI; Sustainable Development Goals; SDG; public perception; synergy; trade-off; Taiwan

\section{Introduction}

The world changes fast, pulled by technological advancements and conceptual paradigm shifts. Artificial intelligence (AI) is a typical case in that its development has already changed people's lives, and more changes, possibly revolutionary transition, are about to come shortly [1-3]. We are using so many technologies related to AI, such as smartphones, social media with algorithms pleasing us, and booking systems while witnessing the continuous technological evolution taking place in an unprecedented way $[4,5]$. Modern society has been developed by humans and empowered by the innovation of technologies, which turn to complicate our lives. Automation, machine learning, and other AI-related technologies can streamline sophisticated systems, making them relatively easy to apply for specified purposes. The emerging use of machine intelligence based on computing capabilities and big data changes the landscape of all aspects of our daily lives, including business, leisure, education, healthcare, utility, and environmental protection [6].

The idea of an "intelligent machine" was introduced by Alan Turing, who named the facility "Turing Machine" in 1937. After this ignition, research and applications of the idea of an intelligent machine or computing underwent several stages of development. 
In the early years, limited computational capacities confined the "intelligence" of appliances. Later in the 1980s, artificial neural networks (ANN) were introduced, accelerating computing algorithms' use of simulating logic embedded in the human cranial nerves system. Today, people employ the term "deep learning" to describe how people try to explore the unidentified capacities of machines to "think like a human" [7]. In history, the term "artificial intelligence" (AI) was introduced by John McCarthy in 1995, who defined it as "the science and engineering of making intelligent machines, especially intelligent computer programs" [8,9]. A three-level category framework was widely accepted, i.e., ANI (artificial narrow intelligence), AGI (artificial general intelligence), and ASI (artificial super-intelligence) $[9,10]$. Briefly speaking, ANI refers to the status quo while AGI indicates the human-level AI, which was thought to be accomplished not long ago. ASI is causing worries and even panic among many people as this AI will have a much more advanced performance than human intelligence. In some other documents, AI was classified as "narrow", "young", and "mature", basically corresponding to ANI, AGI, and ASI with minor differences. The standard prediction of most discussions was the same, i.e., AI will continuously grow, reaching the human-level intelligence capacity, then going further to the point of self-improvement $\mathrm{AI}$ according to various possible development scenarios [3].

\subsection{AI, Risks, and Ethics}

The originality of fear toward AI is understandable as many opportunities have been created, but the "dark side" of AI can also be observed and foreseen along with ubiquitous applications and ambitious development of AI-related technologies. It was argued that the debate on the possibility of impacts of AI on society no longer exists as the discussions turned out to be the area, extent, scale, and timeframe of implications, in what forms and through what ways [11]. If democratic institutions and transparent deliberation cannot be promised, ethical issues arise as AI can enhance the control power of governments, making them act like "big brothers". Monitoring and detecting activities of the citizens, with the help of big data and AI, may cause the problem of "big nudging" and result in loss of human rights, social cohesion, and other precious values for an open and free society [12]. Duality or dilemmas of AI have been discussed by many people, including some pioneer researchers and practitioners. For example, Stuart Russel, one of the authors of a representative AI textbook "Artificial Intelligence: A Modern Approach", claimed that "AI is as dangerous as nuclear weapons" based on the basic scenario of "value misalignment" of AI goals without adequate considerations of human elements and values [13]. Denning and Denning integrated the literature and proposed ten challenging ethical and design dilemmas brought forward by AI, including explainability, fragility, bias, fakes, high costs of reliable training data, military use of AI, weapons and control, employment and jobs, surveillance capitalism, and decision making [2]. Among these terms, surveillance capitalism described the phenomenon that commercial online service captures, collects, and employs personal data upon text posting, commodity purchase, physical movement, and other activities. Environmental issues may also arise as customized information showing in social media may induce more consumption behaviors, primarily unnecessary, resulting in mounting resources and energy uses and snowballing GHG emissions.

In terms of risk management, the ultimate risk of $\mathrm{AI}$ was the loss of lives or dignity of the human being, although AI is "artificial", literately human-made. Catastrophic failure may be caused by AI at different levels, especially after AI becomes self-aware and tries to escape its initial setups. Bostrom and Cirkovic classified the global catastrophic risks into risks from nature, unintended consequences, and risks from hostile acts. AI was shown in two risk categories: risk from unintended consequences such as climate change and pandemics and danger from large troubles caused by modern physics, e.g., accelerators and social collapse [14]. In that book, Yudkowsky argued that people just underestimated the power of intelligence and proposed the connotation of "friendly artificial intelligence". Philosophical and technical failures led to the unwanted results of "AI takes over the 
world", which means AI may reset its goal and the corresponding strategies, leading to unfathomable outcomes and reshaping the world $[1,15]$. The risk of human extinction caused by "unfriendly superintelligent AI" may be eliminated through a wishful engineering strategy: planting ethical principles into the systems [16]. A famous letter issued by the "Future of Life Institute" (FLI), endorsed by some top people in the fields of science and technology such as Elon Musk, Stephen Hawkings, and many other professors and professionals in the research frontiers from the top institutes such as MIT, Harvard, and the AAAI (Association for the Advancement of Artificial Intelligence) in 2015, argued that more research focusing on confining AI in the wall of "human benefit" should be conducted [17]. On the other hand, in terms of extinction, it was also argued that AI could also save people from extinction with "friendly" technologies [9]. In his book "Human Compatible: AI and the Problem of Control", Stuart Russel emphasized what we need to worry about is competence, instead of awareness, of AI, pointing out the core of the issue and indicating that the human is indeed the source of problems [18].

Thus, this raised the issue of AI ethics. Cyberattack and other fraud and theft data problems are among the top ten long-term risks in the WEF Global Risks Report for many years [19]. These intentional malicious uses of AI and other AI-induced problems such as inequality and unemployment were connected to the ethics of AI use [20]. By examining over forty principles mentioned in six representative statements or frameworks related to AI development, Floridi et al. proposed five ethical principles: beneficence, nonmaleficence, autonomy, justice, and explicability [11]. Concerns of automation, collection and manipulation of big data, and the responsibilities of designers and users of those data for the decision-making constituted the ethics of big data. Nevertheless, it was argued that mind-body politics is the core of ethical architecture in terms of "ethical sustainability" [21] Other authors also claimed that the transparency of civil society and democratic institutions are the keys to preventing AI from becoming a wicked ruling tool of governments [12].

Similarly, "soft ethics" was proposed to explain how the governance of the digital society may work upon compliance with regulations. A digital ethical impact assessment can be carried out to confirm if the AI technologies are socially preferable and acceptable, technically feasible, and environmentally sustainable [22]. This could be analogous to the "strategic use of ethics" to promote data sovereignty and strategic autonomy concerning the general cybersecurity issue [23]. Decentralization and democratization were common notions in related discussions, including the oligopoly of centralized mega-companies [24] and intelligent energy management systems [25]. Designing a practical data sovereignty governance framework without encumbering the innovation energies of data economies has been an emerging issue in these years [26,27]. Ideally, data sovereignty can be promised to some extent through reciprocal data-sharing on well-designed platforms in data space systems [28]. Yet, the balance between the benefits of the private and public sectors still played a crucial role in accomplishing the visionary "AI for Good" promoted by the UN and many scholars and practitioners in the field [29-33]. In these booming industries of digital technologies, lining up the common benefit of human society with the commercial incentives of private firms is a challenging task. Collaboration among the key players such as the leading AI companies and labs, governments, independent research communities, and civil society are required [29,31]. To enhance "social good", opportunities and challenges of various key topics, including urban computing, health, environmental protection, and public welfare, were highlighted by the CCC (Computing Community Consortium), IAAA, and OSTP (the White House Office of Science and Technology Policy) of the US. Sustainability was interpreted broadly, considering ecological, social, and economic aspects [32,33].

\subsection{AI and Sustainable Development}

AI for sustainable development (SD) has become the framing of connecting AI to technologies, policies, and various implementations in these years. The triple bottom lines (TBLs) of sustainable development include economic development, social inclusion, and en- 
vironmental performances, indicating that the multiple aspects and diversified applications of AI can be incorporated into the framework of SD. Although AI seems like something enhanced by high technology, human-related values have been highly emphasized. Corresponding to "artificial" intelligence, humanitarian values and humanistic approaches were noted in many discussions. For example, the UN Department of Economic and Social Affairs raised the possible impacts of automation and AI in the coming years, including the substitution, complementarity, and polarization of labor markets and the consequent income redistribution among people. These may result in more severe inequality in life quality and social stability [6]. The humanistic approaches were emphasized when UNESCO discussed how AI could facilitate advanced uses of science and technology and contribute to environmental management and disaster risk reduction in the framework of the science-policy nexus [34]. UNESCO also accentuated concern for ensuring inclusive and equitable use of $\mathrm{AI}$ in education. To leverage $\mathrm{AI}$ to improve the quality of teaching and learning, transparency and accountability of data need to be promised while being used to promote working capabilities and quality of life [35]. In addition to the traditional economic, social, and environmental ones, two more dimensions, technical and individual, were added to a sustainability analysis scheme. The particular dimension focused on the freedom, dignity, and fulfillment of a person. Both positive and negative impacts were identified on all five dimensions, and value-oriented factors such as collaboration, sharing responsibility, and ethics were treated as the keys to sustainable development [36]. The help of big data analysis and other AI-related technologies to enhance sustainable development was confirmed in some new studies [37-39] in which innovation and human-centric approaches played vital roles.

AI and SD-related issues have been explored and discussed in the literature, yet the term "sustainable development" was highlighted only in part of them. Among these, diversified topics/issues in the categories of economy, society, and environment can be found. Applications of AI in marketing, finance, and technologies were highly associated with the economy. The affairs related to education, labor and jobs, and health care belonged to the social aspect. AI for environmental protection, marine conservation, energy efficiency, and agricultural production supported the environment more. It was argued that AI would change the marketing strategies and customer behaviors in the future together with questions of privacy, bias, and ethics [40]. AI has been embedded and employed in some new FinTech tools such as blockchains. These can reduce human-made mistakes and hence improve the quality of financial services, which could also improve social equality, especially for poor people [41]. More applications are about to arrive to solve the complicated market problems [42]. In 2019, more than 100 member states of the UN participated in the International Conference on Artificial Intelligence and Education held by UNESCO in Beijing. They passed the Beijing Consensus on AI and Education. Recommended actions included planning AI in education policies, AI for education management and delivery, AI to empower teaching and teachers, development of values and skills for life and work, AI to offer lifelong learning opportunities for all, promoting equitable and inclusive use of $\mathrm{AI}$ in education, gender-equitable $\mathrm{AI}$, and ensuring ethical educational data and algorithms [43,44]. Early in 2000, as the technological level of AI at that time was somewhat limited, some scholars thought that the development of AI in teaching and learning could build some "electronic villages" or "virtual villages" for people, causing fragmentation of culture, education, and the real lives [45]. In recent years, the disputes of the dual impacts of AI on education have not disappeared. Smart classrooms or online education may benefit some teachers, students, and the general public. However, human development instead of technologies should be treated as the core value of AI in education [46].

As "decent jobs" were the first among the seven critical issues needing prioritized attention proposed by Rio+20 in 2012 [47], the impacts of AI on labor and jobs have also been focused on. Similar to other topics, both positive and negative viewpoints can be found. However, the common one was that $\mathrm{AI}$ and automated technologies would disrupt the labor markets [48-50], including human resources management [51]. AI will basically 
transform most occupations to different degrees. However, a reliable model was yet to be developed by considering the nature of work and the support of relatively high-quality data [48]. Nevertheless, the trend that AI will bring extensive and intensive changes to labor and jobs and also the whole society was a consensus [52]. A human-AI symbiosis, instead of just human identity, will play a significant role in future work scenarios [53]. The psychological responses of the employee to this apparent trend may also connect to the sense of work stability, according to a study on their perception of "smart technology", AI, robotics, and algorithms [54]. How AI can promote health care and related services has also been one of the core topics that many experts and analysts have paid strengthened attention to. In recent years before the COVID-19 pandemic, opportunities and challenges that AI and machine learning technologies may have to improve efficiency, effectiveness, equality, and responsiveness of the health system and then achieving universal health coverage (UHC) have been discussed $[55,56]$. Not only should these new and potentially expensive technologies be applied in developed and prosperous countries/regions but they should also be available in resource-poor situations [57]. These just matched the "value creation" of many emerging business models of health care startups blooming worldwide [58]. The COVID-19 pandemic has very much encouraged interests and practices of applying AI in public health. Right after the outbreak of COVID-19 in late January 2020 in Wuhan, China, Allam and Jones proposed the idea that the "smart city networks" incorporating universal data sharing standards coupled with AI could help the cities around the world understand how much the cases were spreading. This could enhance global understanding and management of biological disasters [59]. One month later, Pirouz et al. employed a binary classification model using $\mathrm{AI}$ and regression analysis to analyze and predict confirmed cases of COVID-19 [60]. McCall argued that AI may help protect healthcare workers and curb the spread of coronaviruses yet cannot replace humans' role. The quality of data is of major concern, and experts must ask the right questions and collect targeted data for analysis. High-quality "big data" and AI can help manage the unusual and massive data from different networks and databases [61,62]. An example that used an ANN-PSO algorithm to predict confirmed cases of COVID-19 found that population density, number of cases 14 days earlier, and humidity were crucial factors for prediction [63].

The adoption of AI in agriculture has also been discussed and implemented for decades. Problems to be examined and solved included those such as crop diseases, storage management, pesticide control, weed management, and irrigation and water management. People paid attention to expert systems' sensors and robots in early times, whereas today, IoT, wireless communications, machine learning, and deep learning with AI have received more attention $[64,65]$. Food security is one of the most mentioned keywords in sustainable development and agriculture. AI-related technologies were thought capable of monitoring and predicting the situation and finding candidate solutions [66]. Smart management of energy and buildings was also a cross-field application of AI for promoting sustainability. "Smart homes" and "intelligent buildings" became modern terms indicating well-controlled electronic facilities, environment, and emissions, basically powered by AI [67,68]. These were further scaled up toward "smart cities" through smart energy management in which smart grids with more renewable energy sources played a significant role $[69,70]$. Energy sustainability in these smart cities could be promoted through smart monitoring and energy system optimization, together with AI [71]. Related technologies are complicated, e.g., deep learning, IoT, data-driven analytics, demand response, interoperability in smart grid, disaggregation techniques in non-intrusive load monitoring, and fraud detection [72]. AI applications in the smart renewable energy sector have been predominantly in the EU to support their aggressive climate-related policies [73].

In the aspect of the environment, $\mathrm{AI}$ and robotics were employed to detect and monitor the environment in relatively early days [74,75]. With their computational capacity and improving algorithms, AI approaches, especially with hybridization techniques, have been developed and applied in hydrology and water resources management, e.g., evapotranspiration estimation and drought prediction, under the threat of climate change [76-78]. AI 
has also been used in real-time calculations of ocean waves or long-term predictions of tidal effects $[79,80]$. A mobile solar-powered automated guided vehicle (AGV) was designed to reduce logistical costs and carbon emissions in reverse supply chain (RSC) practices in a used car company in India, aided by evolutionary optimization algorithms. This representative example showed the new sustainable supply chain management approach with AI and robots [81]. In recent years, AI-based decision support systems have been developed to inform global sustainable development status. Scholars from Singapore and Australia tried to design a human-centric AI-thinking model for non-computer science major users to explore sustainability-related EPI (environmental performance index) data. The predictive analysis indicated that four indicators are most influential, i.e., quality of drinking water, sanitation, lead exposure, and wastewater treatment [39].

\subsection{AI, SDGs, and Survey Studies}

The United Nations has advocated the connotation of sustainable development and global partnership to achieve sustainability of people and the planet [82]. From 2000 to 2015, the UN employed eight Millennium Development Goals (MDGs) to meet the needs of the poorest people in the world. Governments and civil society were the main stakeholders to accomplish the MDGs [83]. In the World Sustainable Development Summit (Rio+20) held in Rio de Janeiro, Brazil, in 2012, the UN parties determined to develop the Sustainable Development Goals (SDGs) to continue the global momentum of effort toward a sustainable future. As presented in "Transforming our World: the 2030 Agenda for Sustainable Development", the SDGs were adopted by the UN General Assembly in September 2015. There are 17 SDGs subordinating 169 targets in the integrated and indivisible framework, symbolizing the balance of the three dimensions of sustainable development, i.e., economy, society, and the environment [84]. The 17 SDGs and the corresponding brief descriptions are listed in Table 1.

Table 1. The brief descriptions of the 17 Sustainable Development Goals (SDGs).

\begin{tabular}{|c|c|c|c|c|c|c|c|}
\hline SDG \# & Description & SDG \# & Description & SDG \# & Description & SDG \# & Description \\
\hline SDG 1 & no poverty & SDG 6 & $\begin{array}{l}\text { clean water and } \\
\text { sanitation }\end{array}$ & SDG 11 & $\begin{array}{l}\text { sustainable cities } \\
\text { and communities }\end{array}$ & SDG 16 & $\begin{array}{l}\text { peace, justice, } \\
\text { and strong } \\
\text { institutions }\end{array}$ \\
\hline SDG 2 & no hunger & SDG 7 & $\begin{array}{l}\text { affordable and } \\
\text { clean energy }\end{array}$ & SDG 12 & $\begin{array}{l}\text { responsible } \\
\text { consumption } \\
\text { and production }\end{array}$ & SDG 17 & $\begin{array}{l}\text { partnerships } \\
\text { for the goals }\end{array}$ \\
\hline SDG 3 & $\begin{array}{l}\text { good health } \\
\text { and well-being }\end{array}$ & SDG 8 & $\begin{array}{l}\text { decent work and } \\
\text { economic growth }\end{array}$ & SDG 13 & climate action & & \\
\hline SDG 4 & $\begin{array}{l}\text { quality } \\
\text { education }\end{array}$ & SDG 9 & $\begin{array}{c}\text { industry, } \\
\text { innovation, and } \\
\text { infrastructure }\end{array}$ & SDG 14 & life below water & & \\
\hline SDG 5 & $\begin{array}{l}\text { gender } \\
\text { equality }\end{array}$ & SDG 10 & $\begin{array}{c}\text { reduced } \\
\text { inequalities }\end{array}$ & SDG 15 & life on land & & \\
\hline
\end{tabular}

In addition to the traditional triple bottom lines (TBLs), i.e., economy, society, and environment, the five pillars or five Ps, people, planet, prosperity, peace, and partnership, as presented in the UN report [84], are one way to classify and summarize the 17 SDGs. However, there are no official or standardized classifications of SDGs in terms of the TBLs or 5 Ps. It has been emphasized that the SDGs are interconnected to each other and should be treated as a cohesive system instead of 17 individual items. Since the draft of SDGs was launched in 2014, categorization of the SDGs in general [85] or according to different issues such as ESG [86,87], mining [88], green economy [89], and digital technology [90] have been explored. The SDGs have been widely accepted and applied in many fields. The linkages, synergies, and trade-offs of specified topics such as academia, media, technology, etc., and the SDGs were of significant concern [81-93]. Unlike the MDGs focusing more on the engagement of the member states, the SDGs count more on diversified relevant 
actors such as business and civil societies for success [94]. The SDGs symbolized and reframed the global trend of adopting sustainability goals systemically and practically. For example, the traditional mindset of "lean" and "agile" practices for supply chain management were integrated and implemented as a "leagile" supply chain guided by the principle of sustainability in an emerging economy, India [95].

Several professional organizations endeavored to find out the possible strategies of guiding the development of advanced technologies such as AI toward a human and sustainable direction. WSIS (World Summit on the Information Society) held a forum in May 2015, before the official pass of the SDGs on that September, and declared the WSIS-SDG Matrix, linking the "Action Lines" with the goals and targets of the SDGs. Although the term AI was not explicitly shown in the matrix, multiple related technologies and applications were included in the lines linked to the SDGs [96]. In June 2017, ITU (International Telecommunication Union) and the XPRIZE Foundation co-organized the "AI for Good"

Global Summit, in which over 500 representatives of the governments, industries, academia, and research institutes participated and discussed how AI could help achieve the SDGs. Health, education, energy, and environmental protection are among the focused fields. Both the promise and the peril of AI were deliberated, with deep considerations of ethical issues and social challenges. The summit then became an annual event, and the platform kept holding online forums and events with the theme "AI for Good" [30]. McKinsey \& Company published a report in 2018 noting the SDGs they referred to in their case studies. SDG 3 (good health and well-being), SDG 16 (peace, justice, and strong institutions), and SDG 4 (quality education) were identified to be included in most cases, 29, 24, 13 times, respectively [33]. Later in 2019, another think tank, 2030VISION, a partnership of business, NGOs, and academia for making a transformative change of technologies to support SDGs, published a report focusing on AI for the SDGs. They argued that AI was already at a critical stage as it became more widely adopted in our lives. Moreover, AI can help people understand and achieve SDGs with dynamic, complex, and interconnected characteristics [97]. Both the opportunities and risk of AI for accomplishing the SDGs were discussed again, emphasizing the importance of moderate regulations [98]. Looking at the 17 goals and 169 targets of the SDGs, Vinuesa et al. employed a consensus-based expert elicitation process to identify the possibilities of synergies and trade-offs of AI. They found that AI can empower 134 targets out of the 169 ones while constraining the other 59 ones. Taking Target 1.1, "By 2030, eradicate extreme poverty for all people everywhere" as an example, image technologies with AI can help discover hotspots of poverty. However, AI would enlarge the gaps of job capacity and requirements between poor and rich people and thus becomes an inhibitor of the target. They also addressed that regulatory insights and schemes are necessary to ensure the values of $\mathrm{AI}$ and the SDGs, i.e., transparency, safety, and ethics [12].

Public perception of AI has been examined and reported for decades, crossing several development stages. Media coverage of AI could reflect how people thought of the related topics. A long-term analysis carried out by Fast and Horvitz analyzed the AI-related articles published by the New York Times from 1986 to 2016 and discovered some general trends. Discussions about AI have surged since 2009, and more optimistic descriptions or statements can be found than pessimistic ones [99]. Similar results were obtained in another similar study with even more extensive media coverage, analyzing over 9000 articles in CNN, USA Today, the Guardian, the Washington Post, and the New York Times from 1980 to 2018. The concept of AI went through fragmentation, and many topics were pooled results of business and scientists [100]. A framing analysis of five American Newspapers from 2009 to 2018 also concluded that business and technology were the main topics in AI-related news coverage. Additionally, benefits were much more frequently mentioned and discussed than risks [101]. The ethical issue of AI, which was treated as the opposing viewpoint in the media, was also analyzed qualitatively. The reports were, in general, thought to be shallow and not informative enough [102]. 
Recently, Wang employed a Python module, "Tweepy", to collect 0.6 million tweets in July 2018 and analyzed them using a sentiment lexicon. The main findings included that more positive words than negative words were connected to discussions related to AI and that the positive and negative feelings for laypeople and computer professionals were not statistically different [103]. Social media posts of applications of AI in specific filed were also collected and analyzed. Gao et al. [104] found that in over two thousand posts on the Sina Weibo Platform in 2017 regarding AI in medical care, most people had a positive attitude toward AI and believed that human doctors' role would be replaced to some extent by AI. Approximately 32,000 tweets from 2007 to 2018 in Brazil were collected and analyzed using the social amplification of risk framework to understand the role of experts in the public perception of AI. It was found that the general positioning of experts instead of actual risk events was the source of the risk perception of the public in Brazil [105].

Although the people's attitudes or perceptions of AI-related digital technology are of interest to many researchers, few official studies in academic forms can be found in the literature. The survey on the attitudes toward the impact of digitization and automation carried out by the European Commission (EU) has been one of the few official large-scale works. So far, it has been carried out three times, in 2012, 2014, and 2017 [106]. The range of areas for this survey covered the impact and use of digital technology (DT), people's perceived skill level of using DT, attitude toward the content on online social networks, attitude toward robotics and AI, use of digital health and care, and people's perceived cybersecurity issues. The 2017 survey found that most of the 27,901 respondents were positive about the impacts of the recent DT on society, the economy, and quality of life; thought themselves skilled in the use of DT in daily lives and work; hardly believed the stories in online social networks; and had a positive attitude to robots and AI. On the other hand, the respondents also worried about the possible job losses brought about by using robots and AI. Regarding data security and sovereignty, the respondents were much more willing to share their health data with medical doctors and healthcare professionals than other public and private sectors. Most respondents cared about privacy and data security [106]. Nevertheless, differences existed among people from different countries in the EC. This information can be treated as the background of people living in these relatively developed western countries. Lozano et al. employed data collected from 6308 people in Spain in 2018 and built a binary logit regression model to discover the dominant factors that can predict the positive attitude toward AI and robotics. In general, Spanish people had a very positive attitude to AI and robotics. Demographic differences could be identified in gender, i.e., males had more a positive perception than females [107].

Differences in AI perception of people to demographic factors were also analyzed in some other survey studies. In a cross-eight-country AI perception survey conducted in 2019, people living in developed countries such as the US, Canada, Australia, and France had a relatively positive attitude toward AI [5]. Applications of AI for education and healthcare raised their hopes. They also found that people from developing countries such as Brazil, Nigeria, and India worried about the possible loss of jobs caused by the widespread use of AI. However, according to the sentimental analysis concerning the openended questions in the survey, they found that people in the developing countries felt more "exciting" and "useful". In contrast, those in developed countries showed more "worrying" about AI, indicating a contradictory phenomenon. A similar study was also performed in 2018 to understand the perceptions toward AI of college students with technical and humanities majors. It was also found that almost $60 \%$ of college students in Romania, a developing country with relatively high incomes, have a positive attitude toward the changes driven by AI in the future. Male students and technical background students have significantly more positive feelings regarding the future of society with AI than female and humanities background students. Technical students also expected a higher level of sustainable development brought about by AI [4].

As we can find many surveys and studies concerning people's knowledge, attitude, skill, behavior, and other perceptions toward AI, most surveys had their respective focuses 
instead of a more integrated and comprehensive understanding of the respondents. Moreover, we can hardly find studies connecting people's perceptions of AI and sustainability issues, although the ultimate risk of $\mathrm{AI}$ is precisely the "unsustainable development" of the human being. Thus, we think that a systemic analysis of how people use and think about $\mathrm{AI}$, their sentimental response toward $\mathrm{AI}$, and the sense of sustainability connected to $\mathrm{AI}$ is necessary. As both the visionary and operational framework of sustainable development (SD) from 2016 to 2030, the SDGs could be severed as the indicators of people's extended cognition and perception regarding $\mathrm{AI}$ and SD. Moreover, many more AI-related survey studies were performed in western countries, but Asian countries actively developed and applied AI technology to ordinary lives [20,108]. Thus, we designed our research to understand how people in a high-tech emerging economy such as Taiwan, in which pioneer research and ICT applications, including AI, are developing, considering $\mathrm{AI}$ and the linkages between AI and the SDGs. We believe that this study can contribute to the literature by offering the background of how people understand and think about AI in eastern societies. More importantly, it would be one of the pioneer studies concerning AI and each of the SDGs based on a survey of the general public.

\section{Materials and Methods}

\subsection{Framework and Design of the Survey}

To understand the characteristics of people's perceptions toward AI technology, we designed a survey to investigate their knowledge, behavior/skill, and affection/attitude connected to AI. In addition, their cognized linkages of AI and each of the SDGs were also included in the survey.

As we did not intend to test people's actual knowledge about AI, we ask how they thought they understood AI and some applications. These can be categorized as "subjective knowledge". There were also several questions to recognize the respondents' behaviors and skills related to AI. The frequency of using AI, intention to understand the development trend of AI, and tendency to learn how to use AI-related appliances were some of the questions. Most questions were allocated to measure people's attitude and affection for AI. Topics of interest consisted of their general attitude toward AI, their opinions on the impacts of AI upon human society, AI governance, AI ethics, and their expectation of AI's daily applications. One feature of this study is investigating how people think of the relationships between AI and the SDGs. The respondents were asked two questions, one for basic understanding and the other for subjective knowledge, before they were ready to answer 17 questions corresponding to the extent of synergy and trade-offs between AI and each of the 17 SDGs.

The aspects and questions of the survey were framed and designed by referring to previous related studies, reports, and many articles in the literature. For example, a study of the college students' perspectives on sustainability of AI [4] and other AI surveys offered materials for the questions of subjective knowledge and some related to people's behaviors and skills $[5,99,109,110]$. For the questions regarding the intention to use AI equipment, we took the technology acceptance model (TAM) as the core assumptions, which argued that the two main factors connecting to an individual's information systems acceptance were "perceived usefulness" and "perceived ease of use" [111]. A semantic differential scale (SDS) was employed to obtain quantifiable measures of people's sentimental response to AI development. These questions were prepared based on the assumption that people's perceptions of the risk and benefit of innovative technologies are interrelated [112]. By considering the scale presented in previous articles [113,114], seven pairs of semantics, four for indicating efficacy and the other three connecting sense of security, were included $[45,107]$. Additional questions related to affection and attitude, items, and descriptions used in some studies aiming to find AI dilemmas for people were referred to [2,3]. The questions regarding AI governance and AI ethics were cited from several studies, e.g., the work published by Dafoe in 2018 concerning global politics and the governance of AI [23], with modifications made according to the local characteristics [2,9,11,13,14,16,20-22,115-117]. 
The questions to understand how people think of the connections, including trade-offs and synergies, of AI to each of the SDGs were designed based on studies relating to systemic relationships of SDGs and different issues [65,82-85]. The structure of the questions and corresponding issues and references are listed in Table 2. Demographic variables were also asked to identify the possible relationships between education, gender, college major, age, location, and the mentioned dependent variables of concern.

Table 2. Questions and corresponding issues and references of the survey.

\begin{tabular}{|c|c|c|}
\hline Topics & Variables and Items & References \\
\hline Demographic variables & $\begin{array}{c}\text { Education, gender, college major, age, } \\
\text { location }\end{array}$ & \\
\hline \multirow{2}{*}{ Subjective knowledge } & Perceived self-understanding of AI & {$[4,99]$} \\
\hline & $\begin{array}{l}\text { Perceived self-understanding of AI } \\
\text { applications }\end{array}$ & {$[4,5,109,110]$} \\
\hline \multirow{3}{*}{ Behavior/skills } & Frequency of using AI & [109-111] \\
\hline & $\begin{array}{c}\text { Habit of understanding trend of AI } \\
\text { development }\end{array}$ & {$[109-111]$} \\
\hline & Tendency of learning AI commodities & [109-111] \\
\hline \multirow{6}{*}{ Affection/attitude } & Sentiment to AI & {$[4,31,45,106-108]$} \\
\hline & Attitude toward AI development & {$[2,111]$} \\
\hline & $\begin{array}{l}\text { Attitude toward "impact of AI to } \\
\text { human society" }\end{array}$ & {$[2,3,11]$} \\
\hline & $\begin{array}{l}\text { Attitude toward AI governance } \\
\text { Accountability/responsibility, civil } \\
\text { participation, AI literacy, confidence in good } \\
\text { management, opinions on AI development, key } \\
\text { factors of successful management or governance }\end{array}$ & {$[2,3,9,11,13,14,16,20-23,115-117]$} \\
\hline & $\begin{array}{l}\text { Attitude toward AI ethics } \\
\text { Role of public interests, role of private interests, } \\
\text { privacy protection }\end{array}$ & {$[2,23,31]$} \\
\hline & Attitude toward AI in daily lives & {$[4,109,110]$} \\
\hline \multirow{2}{*}{ Knowledge for the SDGs } & Basic understanding of the SDGs & {$[12,33,106]$} \\
\hline & Perceived self-understanding of the SDGs & {$[12,33,106]$} \\
\hline AI-SDG connections & $\begin{array}{l}\text { Perceived connections of AI and each of } \\
\text { the SDGs }\end{array}$ & {$[12,65,82,91-93]$} \\
\hline
\end{tabular}

\subsection{Research Questions and Survey Development}

In this study, many research questions were of interest. According to the literature review and the concentrations discussed above, the main concerns of this study include people's subjective knowledge, behavior, skills, affections, attitude toward AI, and related technologies and applications. The respondents' sentimental responses to AI, their ideas of the possible impacts of $\mathrm{AI}$ on our future, and AI's governance and ethical issues in human society are also of significant concern. How people think of the linkages between AI and the SDGs is also the focus. The following are some of the major research questions:

1. How do people in Taiwan perceive their self-understanding of AI and related applications?

2. How popular is AI in Taiwan in terms of the frequency of using AI, intention to learn how to use AI, and understanding of the trend of AI development?

3. What are the people's sentimental responses to AI in Taiwan?

4. How do people in Taiwan think of the opportunities and risks of AI?

5. What are the people's perspectives on management, governance, and related ethic issues connecting to AI in Taiwan?

6. How do people in Taiwan consider the linkages of AI to each of the SDGs? 
7. Are demographic variables such as education, gender, age, college major, and location relevant to the results for the above research questions?

To examine the research questions and accomplish the research objectives, we designed a web-based questionnaire consisting of 26 questions, in which some sub-questions subordinated to each of the questions. The questionnaire was developed through a series of processes. At first, the candidate questions were drafted mainly based on a literature review. The first draft of the questionnaire was sent to several experts in sustainability studies, environmental education, and computer science to ask for their feedback. The modified questionnaire was first distributed to one hundred to two hundred college students and schoolteachers in November 2019 to check its reliability and validity. It was found that the questionnaire had good reliabilities. The Cronbach $\alpha$ for most categories of questions was between 0.68 and 0.84 . The wording of some questions was then modified according to the feedback opinions of those respondents. The revised version of the questionnaire was then reviewed again by an ad-hoc committee organized by several experts to confirm its validity. It was finalized in May 2020. Figure 1 illustrates the process of survey development, sampling, and data analysis. The questions were listed in Appendix A (Table A1).

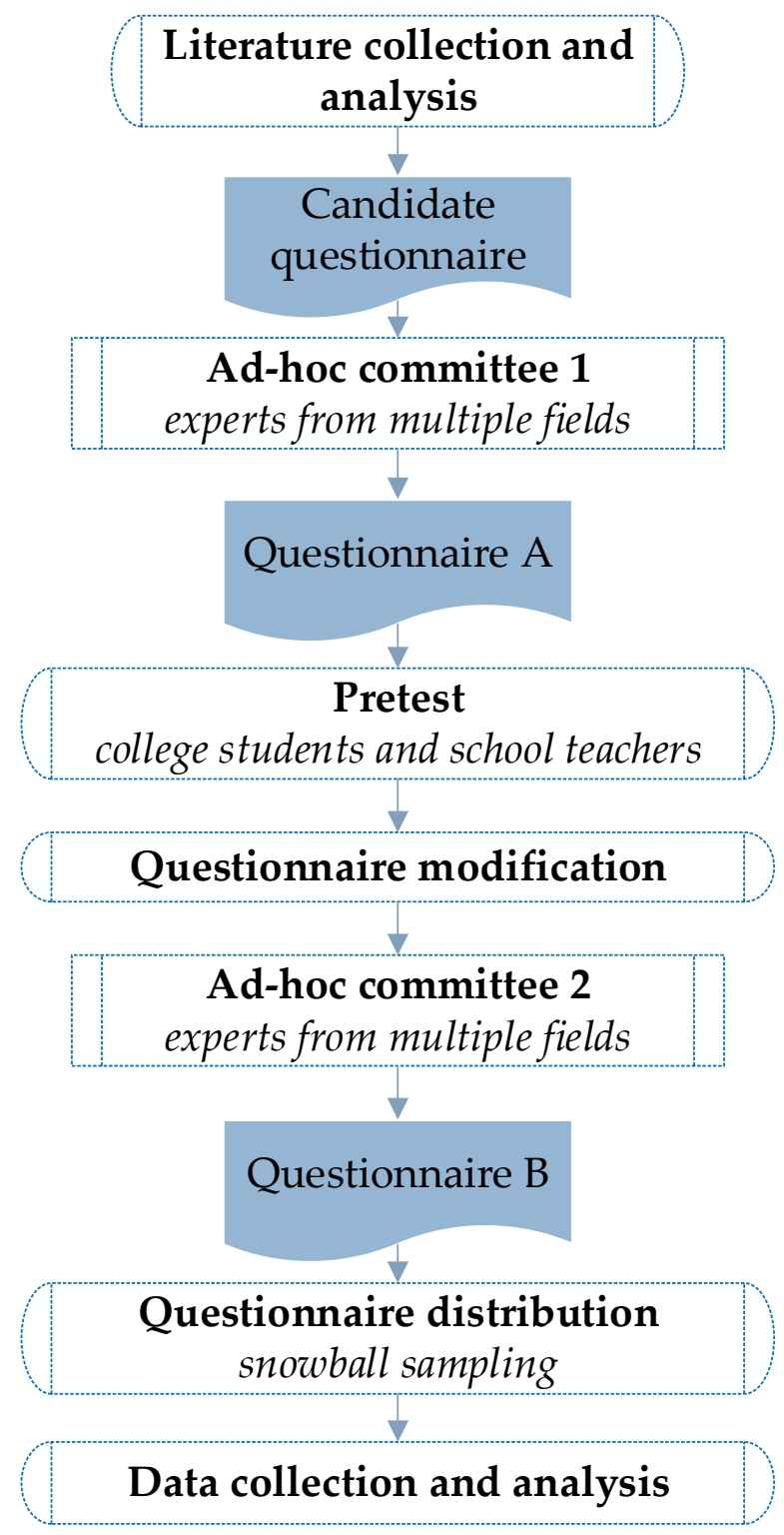

Figure 1. The process of questionnaire development, sampling, and data analysis. 
A group of 10 graduate students at National Taiwan Normal University and several professors around Taiwan distributed the hyperlink of the questionnaire through their social networks and various social media. Over 1200 respondents answered the questionnaire in June and July 2020. Some incomplete or ineffective questionnaires were removed from the database. In the end, we had 1018 effective samples for further analysis. The sampling process could be seen as a convenient sampling, which has been adopted in other survey-oriented studies [118-120]. Possible sampling bias could be checked according to the analysis for different demographic variables.

\section{Results}

Among the 1108 respondents offering effective data, $54.4 \%$ and $45.6 \%$ were female and male. Most respondents were between the ages of $21-30$, with a percentage of $46.9 \%$. Their college majors were diversified, with more with engineering, humanities, and business backgrounds. Over $85 \%$ of them thought they lived in urban areas, which is consistent with the geographic characteristics of Taiwan as it is a crowded and highly urbanized island. Table 3 summarized the variation of demographics of the respondents corresponding to education, gender, college major, age, and location. SPSS 23 was employed as the tool for analyzing the collected data. Descriptive and inferential statistics were carried out to obtain the perspectives of $\mathrm{AI}$ of the respondents, together with their opinions on the linkages of $\mathrm{AI}$ and each of the SDGs.

Table 3. Variation of demographics of the respondents.

\begin{tabular}{|c|c|c|c|c|c|c|c|c|c|}
\hline \multicolumn{2}{|c|}{ Gender } & \multicolumn{2}{|c|}{ Age } & \multicolumn{2}{|c|}{ Location } & \multicolumn{2}{|c|}{ Education } & \multicolumn{2}{|c|}{ College Major } \\
\hline Gender & Percentage & Range & Percentage & Area & Percentage & Current status & Percentage & Field & Percentage \\
\hline female & $54.4 \%$ & $<19$ & $11.7 \%$ & rural & $14.8 \%$ & junior college student & $0.9 \%$ & business & $14.2 \%$ \\
\hline male & $45.6 \%$ & $20-29$ & $46.9 \%$ & urban & $85.2 \%$ & $\begin{array}{l}\text { junior college } \\
\text { graduate }\end{array}$ & $7.4 \%$ & humanity & $12.9 \%$ \\
\hline total & $100.00 \%$ & $30-39$ & $11.8 \%$ & total & $100.00 \%$ & college student & $20.2 \%$ & engineering & $15.0 \%$ \\
\hline & & $40-49$ & $17.3 \%$ & & & college graduate & $31.6 \%$ & others & $57.9 \%$ \\
\hline & & $50-59$ & $9.4 \%$ & & & master student & $15.6 \%$ & total & $100.00 \%$ \\
\hline & & $>60$ & $3.1 \%$ & & & master graduate & $17.0 \%$ & & \\
\hline & & total & $100.00 \%$ & & & doctoral student & $2.7 \%$ & & \\
\hline & & & & & & Ph.D. & $2.0 \%$ & & \\
\hline & & & & & & others & $2.8 \%$ & & \\
\hline & & & & & & total & $100.00 \%$ & & \\
\hline
\end{tabular}

\subsection{Perceived Understanding and Involvement of AI}

Regarding the subjective knowledge of AI, $50.0 \%$ of the respondents thought they understood AI at least to a moderate extent, with $43.3 \%$ identifying themselves as "slightly" understanding AI. These numbers showed that people had high confidence in their understanding of AI. When asked about their involvements with several AI-related goods or services, over $57.7 \%$ of them perceived medium to great extents for participation. The web browser received the highest percentage (79.5\%) among the six items, which were social media, communication media, web browser, mobile payment, health management, and intelligent electronic appliances. Less than $5 \%$ of the respondents thought they had never used products or services related to AI, while $30.5 \%$ "often" or "always" used them. These results showed that people in Taiwan were using AI-related products and thought they were connected to AI.

When asked about their frequencies of using AI products in their daily lives or work, actively understanding the trend of $\mathrm{AI}$, and actively learning how to use AI products, about $40 \sim 47 \%$ of respondents chose "occasionally", and 20 25\% picked "often" or "seldom". They demonstrated a proactive attitude toward AI in the fast trend of development and transformation. Figure 2 shows the distributions of the respondents' opinions on their behaviors and skills of AI. We also found that people in Taiwan treated AI as a friendly product/service instead of as high technology. Approximately $90 \%$ of the respondents thought "AI is easy to learn", "AI can promote quality of life", and "AI can offer useful 
information". However, similar to people in developed countries such as the US, Canada, and France, people in Taiwan had a very positive attitude toward the potentials of improving human lives and admitted the risks of AI. For the possibility of "human lives monitored by $\mathrm{AI}^{\prime}$ ", as many as $40.3 \%$ and $42.0 \%$ of the respondents indicated "extremely possible" and "possible", respectively. Almost $80 \%$ of respondents agreed that AI would increase the unemployment rate. As for the ultimate fear of "humans ruled by AI", only $21.8 \%$ thought it was impossible, and $45.5 \%$ selected "possible" or "extremely possible", as illustrated in Figure 3. The preferences of the respondents can be referred to in the data listed in Table 4 .

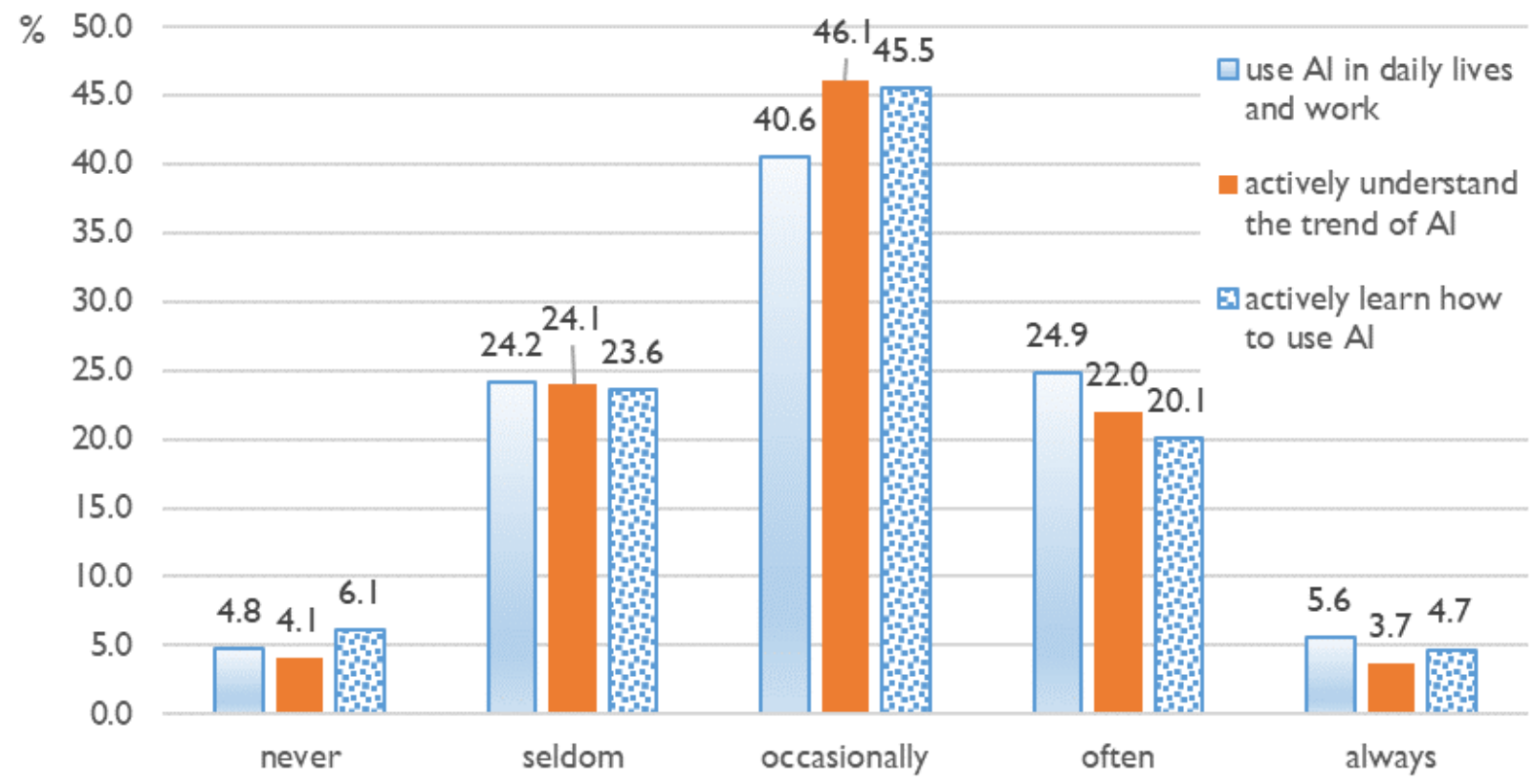

Figure 2. The frequencies of different behaviors and skills related to AI.

extremely

likely, I3.8\%

impossible,

$21.8 \%$

\section{very likely,}

$31.7 \%$

slightly likely,

$32.6 \%$

Figure 3. The responses to "how likely is it that humans will be ruled by AI?". 
Table 4. How the respondents thought of the opportunities and risks of AI.

\begin{tabular}{|c|c|c|c|c|}
\hline AI Can/Will & Extremely Likely & Very Likely & Slightly Likely & Impossible \\
\hline $\begin{array}{l}\text { improve the efficiency of } \\
\text { human society }\end{array}$ & $44.0^{1}$ & 47.0 & 7.3 & 1.2 \\
\hline $\begin{array}{l}\text { allow people have more } \\
\text { time to realize } \\
\text { their dreams }\end{array}$ & 27.0 & 51.0 & 18.1 & 4.0 \\
\hline $\begin{array}{l}\text { offer solutions to } \\
\text { complicated problems } \\
\text { change laypeople's }\end{array}$ & 29.7 & 49.4 & 16.9 & 4.1 \\
\hline $\begin{array}{c}\text { decision-making } \\
\text { capacity } \\
\text { change experts' }\end{array}$ & 30.7 & 47.6 & 18.0 & 3.8 \\
\hline $\begin{array}{l}\text { decision-making } \\
\text { capacity }\end{array}$ & 25.3 & 48.2 & 20.5 & 6.0 \\
\hline monitor human lives & 40.3 & 42.0 & 15.3 & 2.5 \\
\hline $\begin{array}{l}\text { increase the } \\
\text { unemployment rate }\end{array}$ & 34.6 & 45.3 & 16.6 & 3.5 \\
\hline rule the human being & 13.8 & 31.7 & 32.6 & 21.8 \\
\hline
\end{tabular}

${ }^{1}$ Unit: \%.

\subsection{Sentimental Response to $A I$}

Seven pairs of sentimental responses were included in an SDS (semantic differential scale) to understand how the respondents felt about AI. The sentimental response pairs can be classified into two categories: efficacy and sense of security. According to the results shown in Figure 4, people in Taiwan basically had an optimistic or positive feeling about AI and related technologies as over $73 \%$ of the respondents thought they were "convenient", "admirable", "hopeful", and "close". However, on the other hand, when exploring the characteristics of their sentimental responses belonging to "sense of security", we could observe an interesting phenomenon. Over half of the respondents thought AI-related technology was safe, and they did not worry about its future development. Meanwhile, nearly another half were concerned about the risks brought about by AI and expressed relatively conservative opinions on more AI products and services in the future. These results were consistent with previous studies $[5,84]$. People in developed countries had dual or balanced opinions on AI and related technology, i.e., neither too optimistic nor too pessimistic, demonstrating a pattern of "rational optimism".
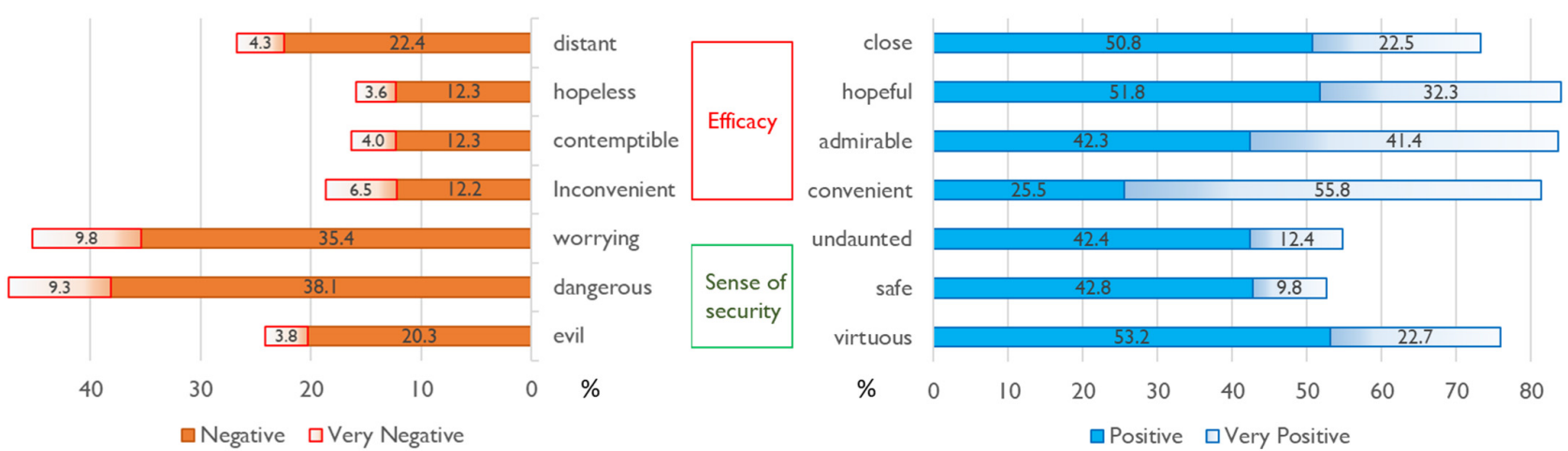

Figure 4. The sentimental responses toward AI of the respondents (two sides along the horizontal axis are asymmetric).

\subsection{Governance and Ethics of AI}

As AI is a concept of emerging technology developing very fast and tends to create opportunities and cause problems simultaneously, governance becomes a key for "AI for 
good", discussed in the preceding [12,21,22]. "Who is responsible?" was the question asked by many stakeholders. Upon being asked this, the respondents picked "international institutes of monitoring AI technological development" as the entities most responsible for the safety of AI, with a percentage of $24.2 \%$. Other objects thought to be important for AI safety included "the government", "the commercial companies using $\mathrm{AI}^{\prime}$, and "the civil society". Surprisingly, only $3.4 \%$ thought the UN should be responsible. Another critical issue for AI governance is the frontier of AI development, e.g., ANI, AGI, or ASI? We found that people in Taiwan tended to keep the control power in human hands as $68 \%$ of the respondents thought that human society should develop AI technology but needs to make sure AI is not self-aware, similar to AGI. Only $1.1 \%$ did not agree that we need to develop AI. Approximately $16 \%$ looked forward to a "brave new future" led by AI as they chose the AI that will handle multiple tasks with an autonomous decision-making capacity. Figure 5 demonstrates the respondents' preferences on the extent of "mature" AI development in the future.

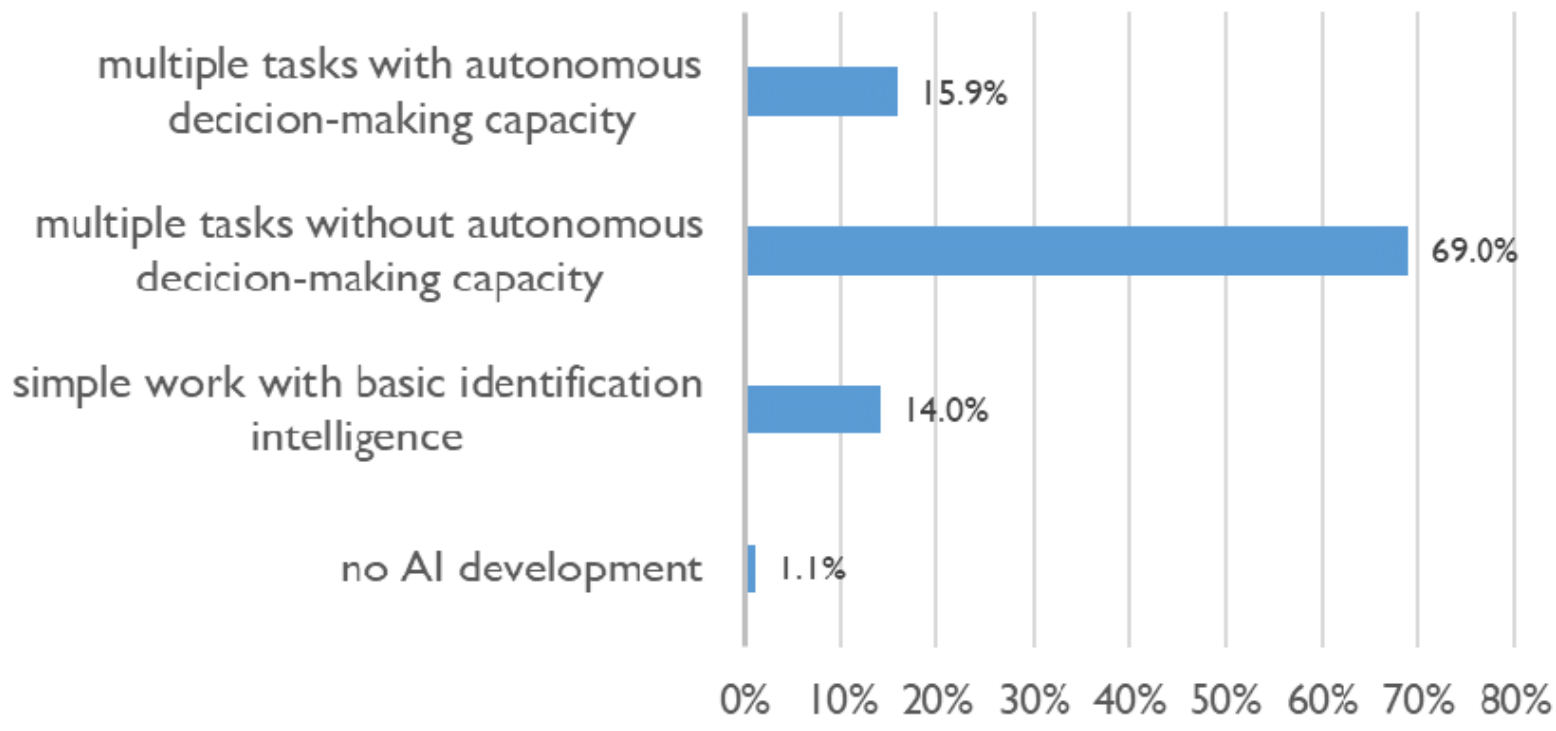

Figure 5. People's preferences on the extent of development of AI.

People in Taiwan would not stop the development of AI because of the risks. Nevertheless, they confirmed the critical importance of regulations for risk management. A total of $97.7 \%$ of them agreed that laws and regulations are essential for AI governance. Ethics, transparency, and democracy were also treated as vital factors for efficacious AI governance. In terms of public participation, more than $85 \%$ of the respondents supported that the citizens should have the right to participate in the legislative processes. Back to reality, most $(73.7 \%)$ respondents felt pessimistic about the virtuous protection of individual information connected to AI. A total of $92.8 \%$ claimed that only with permission of the litigant could information related to AI products or services be collected. This means that "informed consent" could be the baseline for drafting the regulations or laws aiming at AI governance. Another ethical issue was about the roles of private and public interests in developing AI. The respondents in Taiwan took care of realism and idealism altogether. A total of $63.7 \%$ of them realistically agreed that private benefit was the driving force of AI development. More than half of the respondents thought the extension of AI services should be solely based on the need for public profit.

In general, most people in Taiwan realized that AI had already been part of their lives, e.g., internet browsers or social media with AI inside. Most people marked AI as "convenient", "admirable", "hopeful", and "close". For example, 90\% of the respondents believed AI products and services could offer helpful information and elevate life quality. 
Although people worry about the potential risk of AI, they will not stop AI development because of that. They chose to manage and govern AI by way of regulatory tools, and $85 \%$ were prone to participating in the legislative activities. At last, people thought the most critical category of AI literacy for them was about "living with AI" (40.5\%), instead of "managing $\mathrm{AI}^{\prime}$ (26.3\%), "operating $\mathrm{AI}^{\prime}$ (17.1\%), and "working with $\mathrm{AI}^{\prime}$ (16.2).

\subsection{Demographic Differences among the Variables}

Some previous studies found differences existing among groups with different demographic variables, e.g., college major or age. In this study, we conducted the independent $t$-test and ANOVA to discover any statistically significant difference. We picked up four questions related to subjective knowledge, sentimental response, possible impacts, and extent of development of AI to test the potential demographic differences. Male respondents were more confident in AI knowledge than females through a $t$-test $(t=-6.294, p<0.001)$. This result echoes the result obtained by some previous studies [4,121]. Gender differences were also identified for the sentimental response to $\mathrm{AI}$ and its possible impact. For example, for the question on "close vs. distant", male respondents felt significantly closer to AI $(t=-2.521, p=0.12)$. This is also understandable as males were identified as more proactive in using new technologies such as e-learning interfaces [122,123]. Additionally, female respondents expected more impacts brought about by AI than male ones $(t=-2.714$, $p<0.01$ ), especially the impacts on people's decision-making capacities. This finding is consistent with the study carried out in the Netherlands regarding the gender difference in perceptions of automated decision-making by AI [124].

In terms of age, differences were found only in some of the variables for the possible impact of AI. Through conducting ANOVA, significant differences were identified for "change of decision-making capacities of human experts", "human lives monitored by $\mathrm{AI}^{\prime}$, "higher unemployment rates", and "human lives ruled by $\mathrm{AI}^{\prime}$. By employing the Scheffé Method for post hoc tests, various significant differences could be detected. For example, the respondents aged between 50-59 had stronger opinions on the possibility of "human lives ruled by AI" compared with those with ages between 30 to 39. With a similar methodology and process, one significant difference corresponding to the education level of the respondents was found. Compared with college students, master's graduates tended not to think that AI would "change the decision-making capacities of human experts".

A similar process was also employed to test the possible differences corresponding to the three college major groups, i.e., 132 humanities majors, 154 engineering majors, and 149 business majors. The ANOVA found that significant differences in the sentimental response of "evil vs. virtuous" existed among the major groups, with $p=0.029$. The post hoc tests with the Scheffé method were then conducted and confirmed that the business majors marked $\mathrm{AI}$ as more virtuous than the humanities majors, similar to the results of a previous study [4]. It was also found that business majors were less worried about the possibility of human lives being monitored by AI than engineering majors. Table 5 summarizes significant differences of the four questions corresponding to the four demographic variables. Most demographic differences could be found for "the

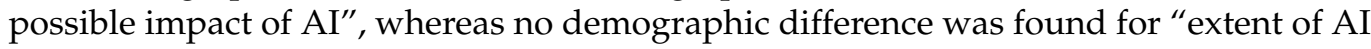
development". The differences of the key variables corresponding to the four demographic variables are shown in Figure 6. As relatively more respondents were in the 20-29-year-old cohort, age could be the index variable to check possible sampling bias. According to the results that most dependent variables were not significantly different corresponding to age, we could judge that the samples could represent the population in general. 
Table 5. The significant differences in the critical questions in terms of the demographic variables.

\begin{tabular}{ccccc}
\hline & $\begin{array}{c}\text { Subjective } \\
\text { Knowledge }\end{array}$ & $\begin{array}{c}\text { Sentimental } \\
\text { Response }\end{array}$ & $\begin{array}{c}\text { Possible } \\
\text { Impacts }\end{array}$ & $\begin{array}{c}\text { Extent of Ai } \\
\text { Development }\end{array}$ \\
\hline gender & $\sqrt{ }$ & $\sqrt{ }$ & $\sqrt{ }$ & \\
age & & & $\sqrt{ }$ & \\
education & & $\sqrt{ }$ & $\sqrt{ }$ & \\
college major & & $\sqrt{ }$ & \\
\hline
\end{tabular}

\section{Subjective knowledge male $>$ female}

\section{Sentimental response close vs. distant male $\leftrightarrow$ female}

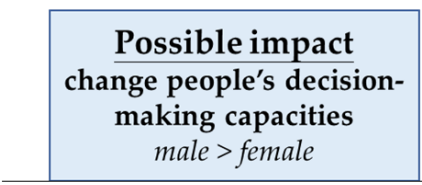

gender

$\frac{\text { Possible impact }}{\text { human lives ruled by AI }}$
$50 \sim 59>30 \sim 39$

age

\section{Sentimental response \\ evil vs. virtuous \\ humanity $\leftrightarrow$ business}

Possible impact
change human experts'
decision-making capacities
college student > master graduate

education
Possible impact

AI monitors human lives

engineering $>$ business

Figure 6. The detailed information on the differences of the key variables corresponding to gender, age, education, and major of the respondents.

\subsection{Perceived Linkages of AI and Each of the SDGs}

In the UN Assembly held in New York in September 2015, the resolution "Transforming Our World" was passed. That was the primary document indicating the UN launched the Sustainable Development Goals (SDGs) as the framework and directives for the human society to promote and implement actions aiming at sustainable development for the whole human being. For the keystone goal, SDG 17: partnership, it was denoted in the document that the developing and the least developed countries should have the ability to collect spontaneous, reliable, and high-quality national data and information in order to monitor their progress toward sustainable development. As AI will inevitably exert a significant, even revolutionary impact on our future, it should be examined with various frames or viewpoints. The SDGs are an integrated, interconnected, and interactive framework consisting of 17 goals in economic, social, and environmental aspects. The whole connotation, as well as each of the SDGs, should be related to AI. We asked the respondents two questions regarding their subjective knowledge of the SDGs. Less than half of them (41.1\%) had seen the logos of the seventeen SDGs before. A total of $43.9 \%$ felt they did not understand the SDGs at all. These results indicated the fact that the SDGs were neither popular nor well-understood in Taiwan. In addition, the respondents would answer seventeen questions corresponding to each of the SDGs as follows: "What do you think of the extent of connection of AI to the SDGs?". They could pick one answer out of "very negative", "negative", "no connection", "positive", and "very positive". For each SDG, a brief phrase in Chinese was offered to let the respondent understand the SDG directly, e.g., "SDG 3: good health and well-being". This expression could alleviate the problem of people's ill-understanding of the SDGs.

To understand the perceptions of AI's linkages and corresponding attributes to the SDGs of different demographic groups, we employed the independent t-test, analysis of variance (ANOVA), and principal component analysis (PCA). We could obtain the whole picture of people's perceived AI-SDG connections through these statistical analysis methods and identify the essential SDGs in terms of both synergy and trade-offs. 


\subsubsection{Distribution of the Attributes of Connection of AI and Each SDG}

Figure 7 illustrates the perceived linkages/connections of AI and each of the SDGs. People in Taiwan in general thought AI had positive connections to the SDGs. "Positive" and "very positive" were counted as "synergy", whereas "negative" and "very negative" were counted as "trade-off" and "no connection" as "neutral". Among the 17 SDGs, SDG 4 (quality education), SDG 9 (industry innovation), and SDG 3 (good health and well-being) obtained the highest supporting rates, approximately $80 \%$. These three SDGs also gained the lowest percentages of "trade-off", less than 7\%. SDG 10 (reduce inequality) was selected as the one with the highest trade-off rate. This showed that more people tended to think more affluent or highly developed countries or groups might have better access to more opportunities in AI-related technology, leading to wider gaps between richer and poorer countries. This inference can also explain why SDG 1 (no poverty) and SDG 8 (decent work and economic growth) obtained the second and third highest trade-off rates. These two SDGs were highly related to employment and income, which AI would significantly impact. Moreover, most respondents considered SDG 5 (gender equality) and SDG 10 (reduce inequality) irrelevant to AI. This is probably because Taiwanese society has been in an atmosphere of equality in terms of gender and education. Thus, people generally would not expect to be excluded from AI technology. Speaking overall, people in Taiwan thought AI development should be based on quality education and industrial innovation, aiming to diminish poverty and reduce domestic and international economic inequality.

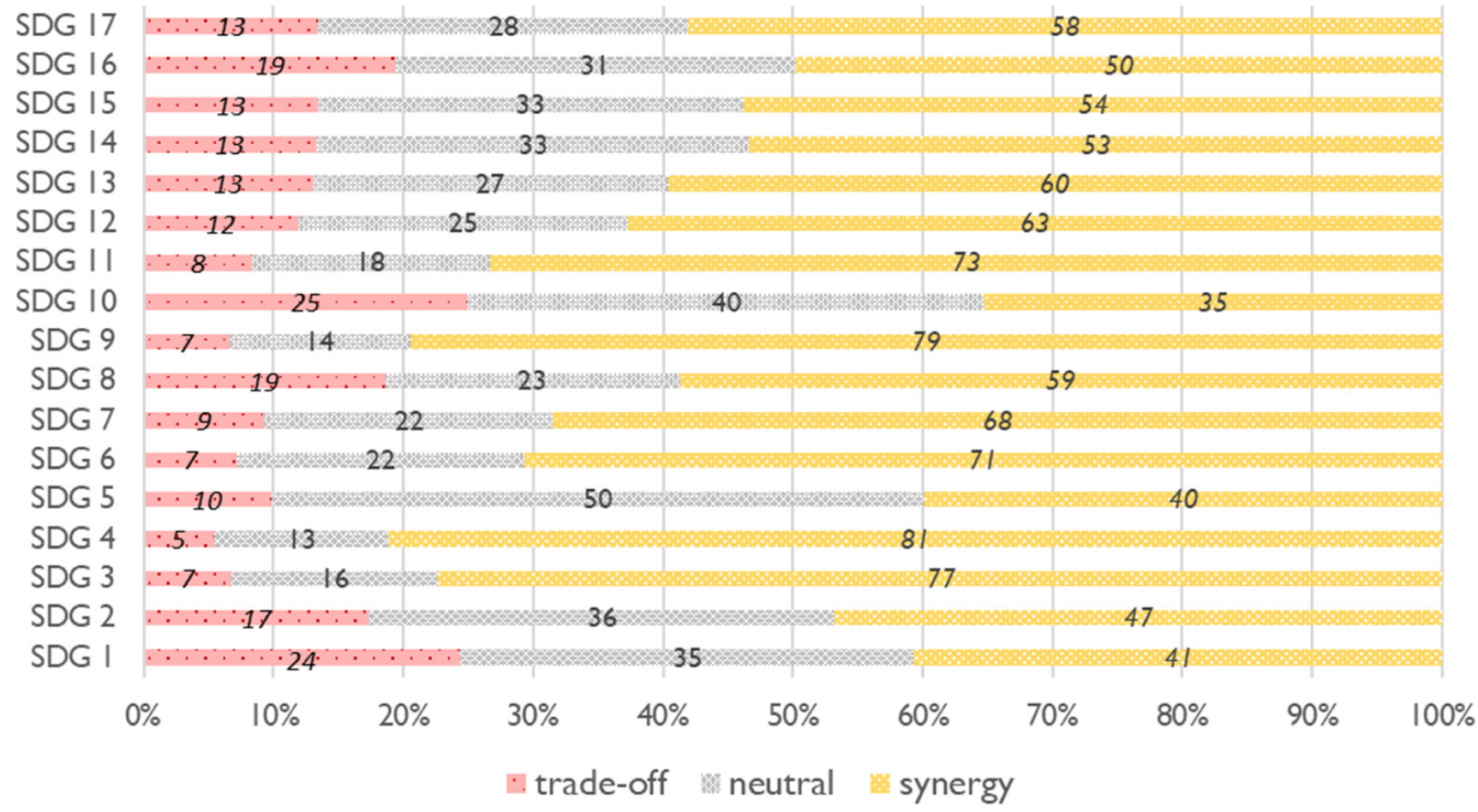

Figure 7. The perceived linkages/connections of AI and each of the SDGs (unweighted).

As the respondents could have five instead of three options when they answered the question, the more extreme selections, i.e., "very negative" and "very positive", might be stressed to reflect the strength of their opinion on the AI-SDG connection. Thus, we weighted the frequencies of these two selections three times and recalculated the distribution of the perceived AI-SDG linkages. As a result, we could find that for each SDG, at least one of the percentages for "positive" and "negative" increased, whereas that for "neutral" decreased accordingly, as illustrated in Figure 8. Thus, the SDGs' new "preference pattern" was similar to the unweighted one but with less indifferent opinions. 


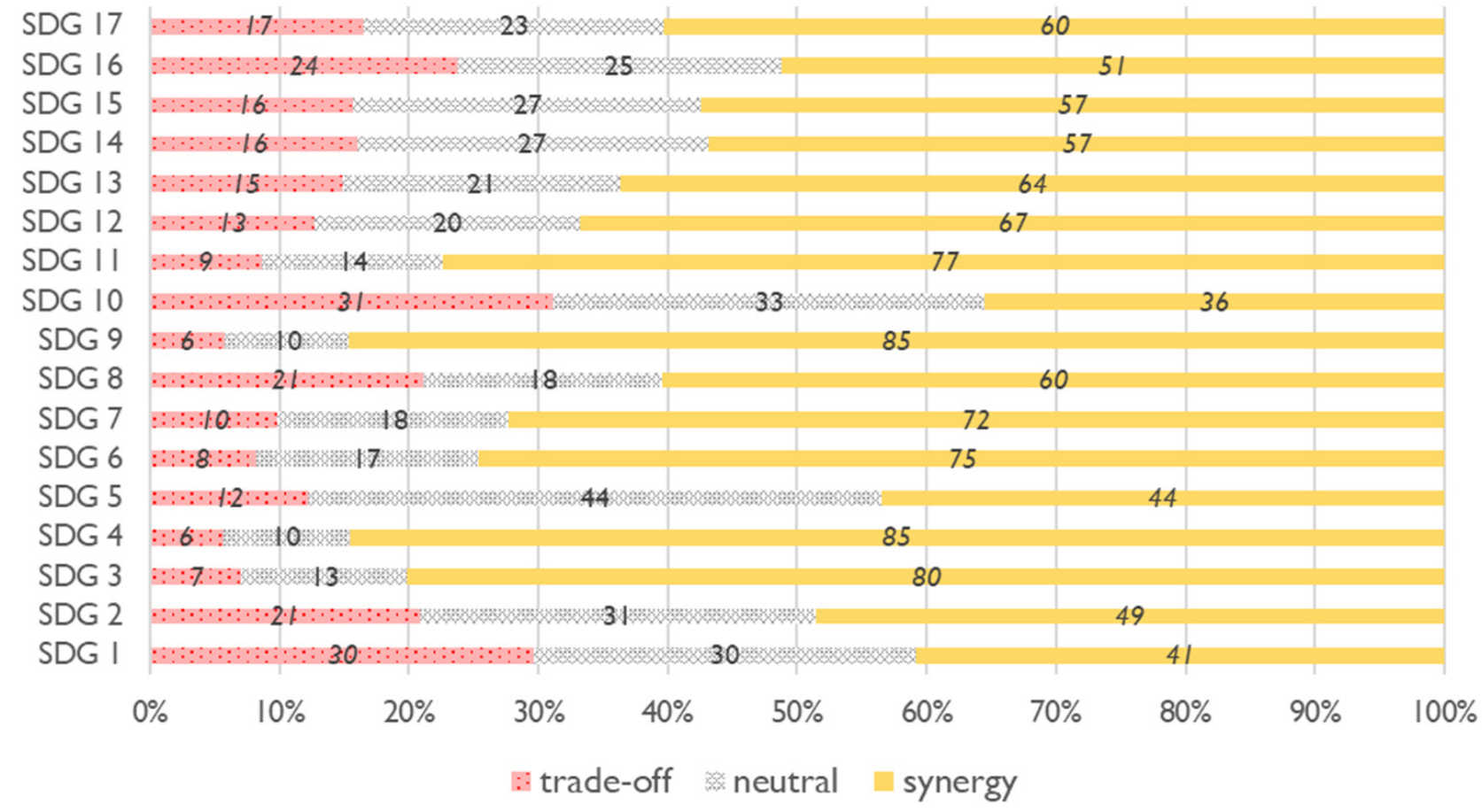

Figure 8. The perceived linkages/connections of AI and each of the SDGs (weighted).

\subsubsection{Demographic Relationships of the Perceived AI-SDG Connections}

Through the independent $t$-test (Welch's $t$-test or unequal variances $t$-test), male respondents were found to have a more positive attitude toward the connections of AI to SDG 8 (decent work and economic growth), SDG 9 (industry innovation), and SDG 17 (partnership) than female ones, with the t-statics and significance in order as 2.219 $(p=0.0035), 3.229(p=0.00)$, and $2.662(p=0.008)$. In addition, by employing ANOVA, we found that the perceived AI-SDG connections of SDG 1 (no poverty), SDG 3 (good health and well-being), SDG 4 (quality education), SDG 9 (industry innovation), SDG 11 (sustainable cities), and SDG 12 (responsible consumption and production) had significant differences among different age cohorts. The $\mathrm{F}$ or Welch-t and significance in order are $2.401(p=0.05), 3.571(p=0.007), 4.304(p=0.002), 10.228(p=0.000), 4.668(p=0.001)$, and 3.014 (0.018). After conducting the post hoc Games-Howell test, compared with other age cohorts, people 20-30 years old had significantly positive AI-SDG perception of SDG 4, SDG 9, and SDG 11.

When exploring whether education might influence the perceived AI-SDG connections, we identified statistically significant different scores among the three groups with varying levels of education (75 for junior college, 321 for college, and 173 for master's graduates) $(\mathrm{F}=3.899, p=0.021)$. Moreover, significant differences in AI-SDG perception for SDG 3, SDG 4, and SDG 13 (climate action) were also found among the respondents with different levels of education, with the Welch-t and significance as $2.869(p=0.003)$, $6.106(p=0.003)$, and $4.533(p=0.012)$, respectively. Through a post hoc comparison, it was recognized that master's graduates and college graduates had more positive AI-SDG perceptions for SDG 3 and SDG 4 than junior college graduates. Moreover, master graduates felt more encouraging about SDG 13 than college graduates; college graduates felt more affirmative toward SDG 9 than junior college graduates. As for college majors, we carried out ANOVA to understand the difference in perceived AI-SDG connections concerning the three major groups, i.e., 132 humanities majors, 154 engineering majors, and 149 business majors. It was found that significant perceived AI-SDG connection differences existed for SDG 8 (Welch- $\mathrm{t}=4.998, p=0.007$ ) and SDG 16 (peace, justice, and strong institutions) 
$(\mathrm{F}=3.077, p=0.047)$. Further paired comparisons generated several results: business majors felt more positive AI-SDG linkages for SDG 8 and SDG 16 than engineering majors; business majors had more favorable feelings toward SDG 8 than humanity majors. Altogether, SDG 9 was mostly identified as significantly more positive demographically. The SDGs and corresponding demographic variables mentioned above were listed in Table 6. It could be observed that stronger feelings about the AI-SDG connections or linkages occurred for the SDGs related to science, technology, knowledge, and economics.

Table 6. The SDGs with significant differences in the perceived AI-SDG connections in terms of demographic variables.

\begin{tabular}{|c|c|c|c|c|c|c|c|c|}
\hline $\begin{array}{l}\text { Demographic } \\
\text { Variable. }\end{array}$ & 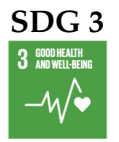 & 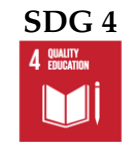 & 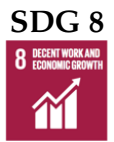 & SDG 9 & 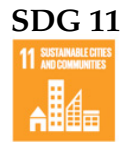 & 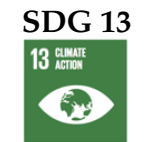 & 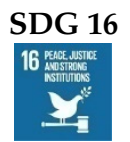 & 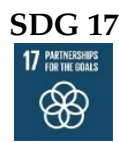 \\
\hline gender & & & male> & male $>$ & & & & male> \\
\hline age & & $20 \sim 30>$ & & & $20 \sim 30>$ & & & \\
\hline education & & $\begin{array}{c}\mathrm{MG}, \mathrm{CG} \\
>\mathrm{JCG}\end{array}$ & & $\mathrm{CG}>\mathrm{JCG}$ & & $\mathrm{MG}>\mathrm{CG}$ & & \\
\hline college major & & & $\begin{array}{l}B>E \\
B>H\end{array}$ & & & & $\mathrm{~B}>\mathrm{E}$ & \\
\hline
\end{tabular}

MG: master's graduate, CG: college graduate, JCG: junior college graduate, B: business, E: engineering, H: humanities.

\subsubsection{The Principal Component Analysis of the Perceived AI-SDG Connections}

The triple bottom lines (TBLs) of sustainable development are economy, society, and environment. The seventeen SDGs can also be classified into three categories. However, according to multiple points of view, one SDG could be classified into different groups. In general, researchers categorized the SDGs based on the framings of their profession, which were similar but not identical. From either the angle of ecology of Folke et al. [125] or the viewpoint of economics of Barbier and Burgess [86], SDG 8 and SDG 9 have been treated as economic aspects. Additionally, the consensus in these two studies also included that SDG 4, SDG 5, and SDG 16 should be social goals, and SDG 13, SDG 14 (life below water), and SDG 15 (life on land) should be environmental goals. However, for the remaining SDGs such as SDG 1, SDG 2 (zero poverty), SDG 3, and SDG 7 (affordable and clean energy), Barbier and Burgess thought these should be classified as economic goals [112]. In contrast, Folke et al. treated them as social goals [125]. In reality, socio-economic data have been collected and analyzed in many public and private sectors. For example, in a country health ranking announced by the University of Wisconsin, social and economic factors consisted of education, employment, income, family and social support, and community safety [126]. The World Economic Forum (WEF) launched the Global Social Mobility Index, emphasizing that individuals' opportunities in life remained tied to their socio-economic status at birth and embedded historical inequalities [127]. This background offered a possibility to rethink the SDG classification according to the survey on the perceived AI-SDG connections.

We carried out PCA to simplify the dimensionalities of the 17 SDGs by capturing their common and specified characteristics based on the data for the perceived AI-SDG connections of the 1108 respondents. We identified three components that can explain the framing of how people in Taiwan thought about the SDGs under the connotation of AI. The three components or categories and the corresponding SDGs are as follows: "science and technology", including SDG 3, SDG 4, SDG 6, SDG 7, and SDG 9; "society and economy", including SDG 1, SDG 2, SDG 5, SDG 8, SDG 10, SDG 16, and SDG 17; and "environment", including SDG 13, SDG 14, and SDG 15. The setting of these three components could explain approximately $64 \%$ of the variance. Moreover, the internal consistencies for all components exceeded $85 \%$, and the overall reliability was as high as $93 \%$. The key statistics of the PCA and the resulting framework of the SDGs could be found in Table 7. 
Table 7. The Principal Component Analysis and reliability analysis of the perception of the AI-SDG linkage.

\begin{tabular}{|c|c|c|c|c|c|c|}
\hline Component & SDG & Loading & $\begin{array}{c}\text { Explained } \\
\text { Variability \% }\end{array}$ & $\begin{array}{c}\text { Cumulated } \\
\text { Explained } \\
\text { Variability \% }\end{array}$ & Cronbach's $\alpha$ & Cronbach's $\alpha$ \\
\hline \multirow{7}{*}{$\begin{array}{l}\text { Science and } \\
\text { Technology }\end{array}$} & $\begin{array}{l}\text { SDG 3: Good health and } \\
\text { well-being }\end{array}$ & 0.727 & \multirow{7}{*}{48.73} & \multirow{17}{*}{64.16} & \multirow{7}{*}{0.888} & \multirow{17}{*}{0.933} \\
\hline & $\begin{array}{l}\text { SDG 4: Quality } \\
\text { education }\end{array}$ & 0.830 & & & & \\
\hline & $\begin{array}{l}\text { SDG 6: Clean water and } \\
\text { sanitation }\end{array}$ & 0.609 & & & & \\
\hline & $\begin{array}{l}\text { SDG 7: Affordable and } \\
\text { clean energy }\end{array}$ & 0.525 & & & & \\
\hline & $\begin{array}{l}\text { SDG 9: Industry, } \\
\text { innovation, and } \\
\text { infrastructure }\end{array}$ & 00.893 & & & & \\
\hline & $\begin{array}{l}\text { SDG 11: Sustainable } \\
\text { cities and communities }\end{array}$ & 0.673 & & & & \\
\hline & $\begin{array}{l}\text { SDG 12: Responsible } \\
\text { consumption and } \\
\text { production }\end{array}$ & 0.355 & & & & \\
\hline \multirow{7}{*}{$\begin{array}{l}\text { Society and } \\
\text { Economy }\end{array}$} & SDG 1: No poverty & 0.844 & \multirow{7}{*}{8.74} & & & \\
\hline & SDG 2: Zero hunger & 0.583 & & & & \\
\hline & SDG 5: Gender equality & 0.559 & & & & \\
\hline & $\begin{array}{l}\text { SDG 8: Decent work and } \\
\text { economic growth }\end{array}$ & 0.618 & & & & \\
\hline & $\begin{array}{l}\text { SDG 10: Reduced } \\
\text { inequalities }\end{array}$ & 0.939 & & & 0.000 & \\
\hline & $\begin{array}{l}\text { SDG 16: Peace, justice, } \\
\text { and strong institutions }\end{array}$ & 0.727 & & & & \\
\hline & $\begin{array}{l}\text { SDG 17: Partnerships for } \\
\text { the goals }\end{array}$ & 0.548 & & & & \\
\hline \multirow{3}{*}{ Environment } & SDG 13: Climate action & -0.747 & \multirow{3}{*}{6.69} & & \multirow{3}{*}{0.920} & \\
\hline & $\begin{array}{c}\text { SDG 14: Life below } \\
\text { water }\end{array}$ & -0.942 & & & & \\
\hline & SDG 15: Life on land & -0.924 & & & & \\
\hline
\end{tabular}

This classification reflected the mindset of people in Taiwan when they judged the linkages of each SDG to AI, which was not identical with those proposed by experts according to their professional lens. We took the idea of Vinuesa et al. [60], illustrating the distribution of the positive, neutral, and negative opinions on the AI-SDG connections corresponding to the categories of "science and technology", "society and economy", and "environment" (Figure 9). About $80 \%$ of the respondents tended to think that SDG 4 and SDG 9 in the category of "science and technology" had the most robust positive connections to AI. On the other hand, people in Taiwan generally indicated that those SDGs belonging to "society and economy" might have more trade-offs related to AI. The two highly inequality-associated SDGs, SDG 5 and SDG 10, with the most perceived percentages irrelevant to AI, also belonged to this category. 


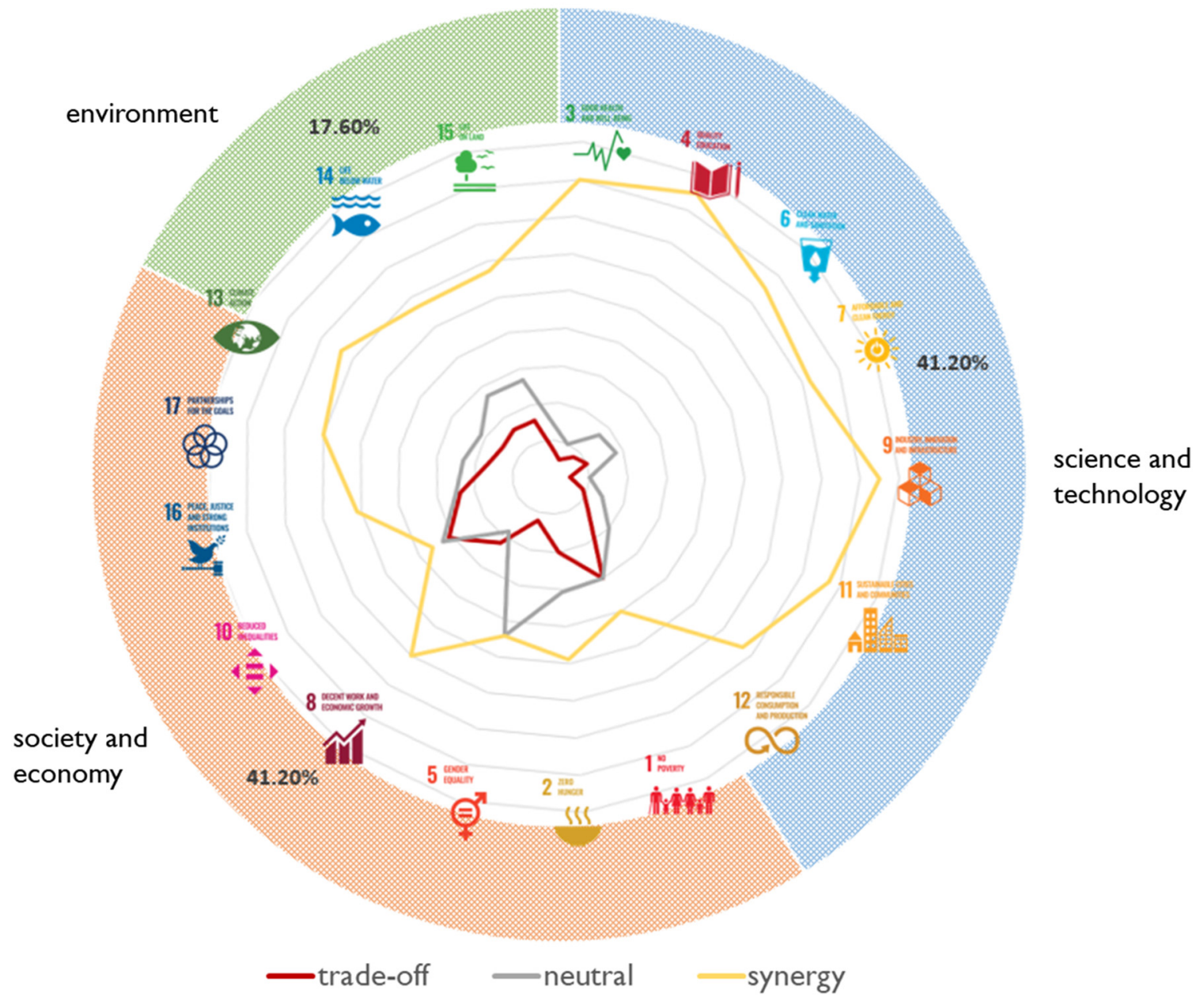

Figure 9. The distribution of the percentages of the positive, neutral, and negative opinions on the AI-SDG connections corresponding to the three categories.

It can also be observed from Figure 8 that more people in Taiwan had a favorable opinion on the AI-SDG linkages for those SDGs in the "science and technology" category than those in the "society and economy" category. Additionally, more respondents thought the SDGs in the category "society and economy" were neutral in terms of the AI-SDG connection than those SDGs in the category "science and technology". This overall picture was consistent with the results obtained from the descriptive statistical analysis. Furthermore, more respondents thought the SDGs relating to inequality were not linked much to AI. Finally, the respondents expected that AI development can promote SDG 3 (good health and well-being), SDG 4 (quality education), SDG 6 (clean water and sanitation), SDG 7 (affordable and clean energy), SDG 9 (industry innovation), SDG 11 (sustainable city), and SDG 12 (responsible consumption and production). This can be interpreted as education playing as the base for constructing a sustainable AI-aided town with an embedded innovative circular economy and high-quality water and energy services, making the residents live healthier lives. Figure 10 integrates the average percentages of perceived AI-SDG connections of all SDGs in each SDG category. This can also show the trend that the "science and technology" SDGs were evaluated as the most favorable for the AI-SDG relationship, followed by those in "environment" and then those in "society and economy". The particular characteristic of being the residents of a "science and technology" island can be revealed in these numbers and diagrams. This result can be analogous to a study conducted in Italy concerning the risk awareness of the "big four's" youngest consultants in the emerging field of e-waste management. Financial and economic risks were of major 
concern, followed by environmental and technological risks. Cyber threats related to personal data were basically ignored [128].

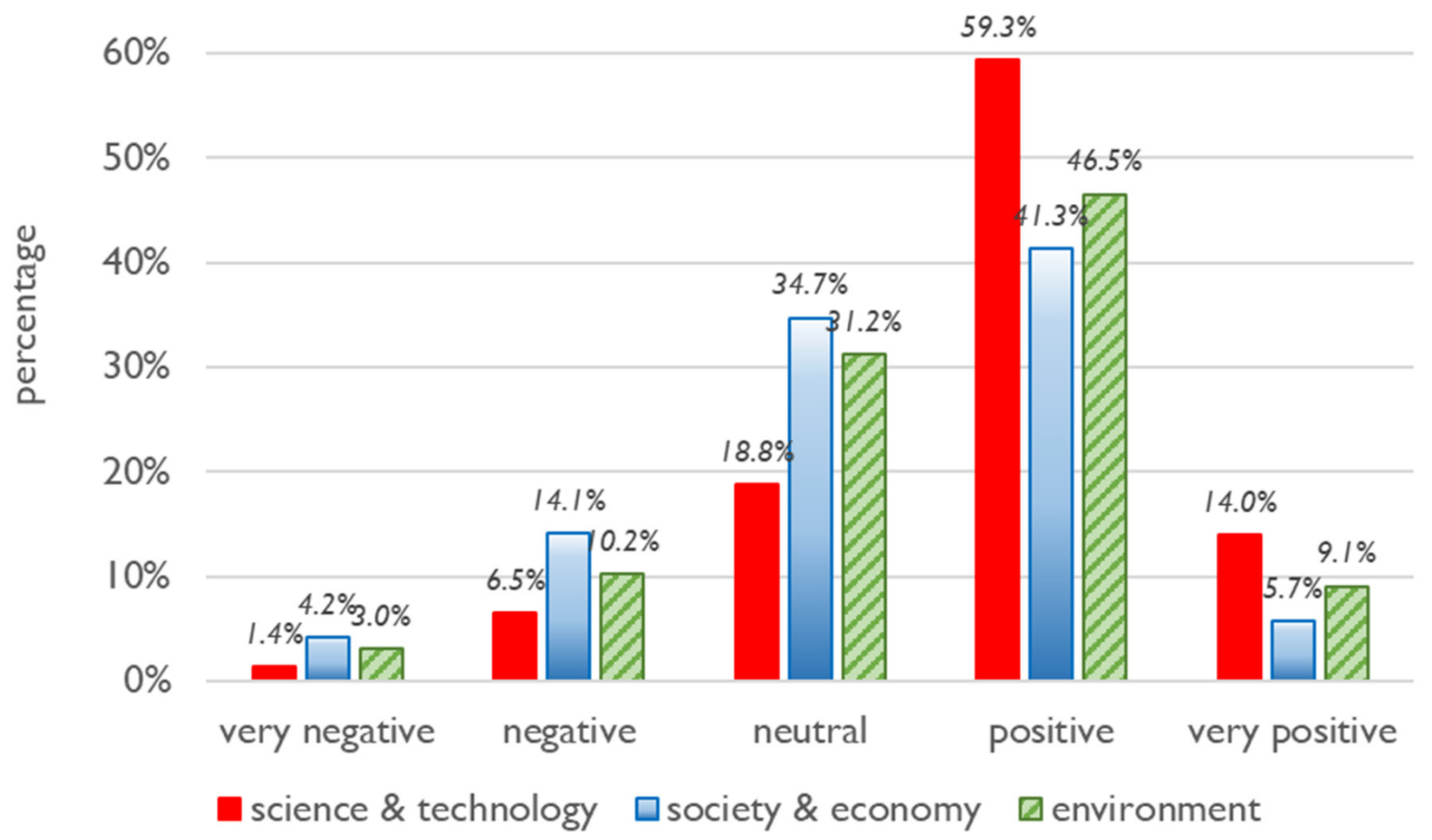

Figure 10. The average percentages of perceived AI-SDG connections of the SDGs in each category.

To understand the correlations among the key concepts of AI perceptions, we chose various concepts consisting of multiple variables and conducted the correlation tests many times. In the end, we selected three concepts of interest: "sense of safe $\mathrm{AI}^{\prime}$, "perceived AI risk", and "thrust of AI with risk under control". Combining these three variable groups with the perceived AI-SDG connections corresponding to the three categories, Table 5 demonstrated the relationships among these key concepts or composed variables. For example, a higher sense of safe AI implied a higher sense of efficient AI, with intermediate correlation $(r=0.374, p<0.01)$ and higher trust of AI with risk under control $(r=0.349$, $p<0.01$ ). This showed that people with a belief in the safety of AI, in general, had higher efficacy toward AI development. However, these people were not naïve as the trust in AI with risk under control was also linked to the perceived AI risk with intermediate correlation $(r=0.316, p<0.01)$. The correlations among the three key concepts and the three categorized AI-SDG linkages were weak. One of the intermediate correlations can be found between the trust in AI with risk under control and the perceived AI-SDG linkages for the "society and economy" category $(r=0.330, p<0.01)$. Strong correlations can be found among the three categorized AI-SDG linkages, representing a synergized point of view among the three categories of SDGs when the respondents considered AI. Table 8 listed the correlation coefficients and p-values of the combinations of the multiple variables. 
Table 8. The relationships among AI perceptions and categorized AI-SDG linkages.

\begin{tabular}{|c|c|c|c|c|c|}
\hline $\begin{array}{l}\text { Correlation } \\
\text { Coefficient } \\
(p \text {-Value })\end{array}$ & $\begin{array}{c}\text { Sense of Safe AI } \\
(\mathrm{M}=2.56 ; \mathrm{SD}=0.72)\end{array}$ & $\begin{array}{c}\text { Perceived AI Risk } \\
(\mathrm{M}=2.11 ; \mathrm{SD}=0.67)\end{array}$ & $\begin{array}{c}\text { Trust of } \\
\text { AI with Risk } \\
\text { under Control } \\
(\mathrm{M}=2.12 ; \mathrm{SD}=0.55)\end{array}$ & $\begin{array}{c}\text { AI-SDG } \\
\text { Science-Technology } \\
(\mathrm{M}=3.78 ; \mathrm{SD}=0.63)\end{array}$ & $\begin{array}{c}\text { AI-SDG } \\
\text { Society-Economy } \\
(M=3.30 ; S D=0.68)\end{array}$ \\
\hline Perceived AI risk & $\begin{array}{c}0.219 \\
(0.000)\end{array}$ & & & & \\
\hline $\begin{array}{l}\text { Trust of AI with risk } \\
\text { under control }\end{array}$ & $\begin{array}{c}0.349 \\
(0.000)\end{array}$ & $\begin{array}{c}0.316 \\
(0.000)\end{array}$ & & & \\
\hline AI-SDG & 0.106 & 0.027 & 0.175 & & \\
\hline science-technology & $(0.001)$ & $(0.388)$ & $(0.000)$ & & \\
\hline AI-SDG & 0.233 & 0.127 & 0.330 & 0.672 & \\
\hline society-economy & $(0.000)$ & $(0.000)$ & $(0.000)$ & $(0.000)$ & \\
\hline AI-SDG & 0.169 & 0.029 & 0.193 & 0.662 & 0.648 \\
\hline environment & $(0.000)$ & $(0.363)$ & $(0.000)$ & $(0.000)$ & $(0.000)$ \\
\hline
\end{tabular}

\section{Discussion}

It is the basic assumption of modern economics that people want to be better off after a decision. Yet, human development since the industrial revolution has brought about environmental degradation, social disparity, resource depletion, conflicts, and even wars among groups and countries. These were the primary reasons why international organizations such as the UN initiated, advocated, and promoted the concept of sustainable development, anticipating a balanced roadmap of human development among economic, social, and environmental objectives. Along with the science and technology development, AI has now been something that is exerting revolutionary transformation upon human society. It is almost impossible to stop the development of more advanced AI technologies because of people's needs. At the same time, we also are anxious about the likelihood of amplifying gaps among people's welfares and accelerating the collapse of our civilization. The terms dilemma and trilemma apply to these issues. Just like other issues such as climate change for which the trend is evident and irreversible, people have balanced or polarized thoughts about them.

We can hardly deny that AI-related technologies, e.g., big data and machine intelligence, have pushed our daily lives and future in an unprecedented way $[1,4,5]$. According to many previous studies, education, jobs, health care, utility, and environmental protection are topics connected to AI and considered by more people [6]. At the same time, people are also worried about AI development as AI may have a more advanced performance than humans, as expected. With both the bright and dark sides taken into consideration [2,13], we developed a survey to understand how people in Taiwan, an ICT pioneer island and high-tech emerging economy, perceive AI. As the SDGs of the UN are the framework and tool for countries, businesses, organizations, and other stakeholder groups to depict and monitor their status and progress of sustainable development, how people think of AI with the lens of the SDGs could be helpful information. In the questionnaire, we included people's knowledge, behavior/skill, and affection/attitude related to AI, together with their perceived linkages of AI of each of the seventeen SDGs. A total of 1018 effective samples of Taiwan's residents were collected.

Half of the respondents thought they understood AI at least modestly, showing high confidence in their AI knowledge. On the other hand, people showed a high level of support toward $\mathrm{AI}^{\prime}$ s capacity to improve human lives but at the same time admitted that human lives could be potentially monitored or even ruled by AI. The information demonstrated in Figure 2 and Table 2 indicates that people in Taiwan were highly involved in AI technology, had a very positive attitude toward AI, and believed $\mathrm{AI}$ is also risky. They were similar to people in developed countries such as the US, Canada, and France in a cross-country AI perception survey [5] and a media analysis [97] carried out in recent years. The balanced and practical points of view toward AI of people in Taiwan were obvious. People tended to accept and use new technologies but were not too naïve to neglect the possible corresponding prices. These characteristics could be found through viewing the 
sentimental response of the respondents. Approximately three-quarters of them thought of AI as "convenient", "admirable", "hopeful", and "close". However, in terms of a "sense of security", although AI was not thought of as "evil", most people felt it was "worrying" and "dangerous". People in Taiwan could be "rational optimists" regarding AI, as they thought very positively toward AI while understanding the reality that problems, even threats, exist in many domains. For the sensitive question regarding how advanced AI will go forward, nearly $70 \%$ of the respondents preferred that AI be able to conduct multiple tasks without an autonomous decision-making capacity. They did not want AI to become self-aware. This result confirmed again that people in Taiwan tend to develop AI but with a well-defined limitation.

The survey results on AI governance and the driving force of AI development revealed that people in Taiwan believed in democracy and capitalism. More respondents picked "international institutes of monitoring AI technological development" as the entities most responsible for AI safety, higher than the government or corporate AI users. They were also eager to have AI-related regulations and be active in participating in the legislative processes. They insisted on data sovereignty as over $90 \%$ of the respondents would ask for permission before their data collected by AI could be used for specific purposes. On the other hand, they also understood the reality, and more than $70 \%$ thought their data would not be protected. Moreover, more than $60 \%$ of the respondents realistically agreed that private interests were the driving force of AI development. More than $50 \%$ thought that AI service development should be based on public interests. In general, people in Taiwan took care of idealism concerning civil rights and data sovereignty and realism relating to business incentives and poor data security altogether.

AI can augment the efficiency of tasks for many issues in many fields. Thus, AI has the capacity to help realize sustainability in different aspects. Yet, the SDGs and interactive systems are integrated with synergies and trade-offs among the goals and targets. How the respondents think of $\mathrm{AI}$ in terms of the 17 SDGs may reflect the relative importance of connections of $\mathrm{AI}$ and these different aspects. The fact that people in Taiwan generally thought AI had positive connections to the SDGs was consistent with their proactive attitude toward AI. SDG 4 (quality education), SDD 9 (industry innovation), and SDG 3 (good health and well-being) obtained the highest supporting rates, as many as $80 \%$ of respondents reflected that people in Taiwan thought AI could most help promote education, industry innovation, and health. On the "negative" side, SDG 10 (reduce inequality), SDG 1 (no poverty), and SDG 8 (decent work and economic growth) were the top three SDGs with the highest trade-off rates. This signified that inequality issues connected to work and income were relatively the central concern of people in Taiwan. At the same time, the two SDGs pertaining to equality were thought to be the most irrelevant to AI. We could also argue that the society of Taiwan has already been in a relatively similar condition in terms of education or other resource allocation issues. With all of these taken into account together, we might claim that people in Taiwan thought AI development should be based on quality education and industrial innovation, aiming to diminish poverty and reduce domestic and international economic inequality.

Through carrying out the principal component analysis (PCA), the 17 SDGs were classified into three components, "science and technology", "society and economy", and "environment". This setting could capture their common and specific characteristics based on the collected AI-SDG linkage data. We also found that more people in Taiwan had a favorable opinion on the AI-SDG linkages for those SDGs in the "science and technology" category. Altogether, stronger feelings about the AI-SDG connections occurred for the SDGs related to science, technology, knowledge, and economics, while the environment and resources were treated as the base. Through considering the characteristics found from the analysis, we can conclude that education played the role of the base for constructing a sustainable AI-aided town with an embedded innovative circular economy and highquality water and energy services, making the residents live healthier lives. 


\section{Conclusions}

Through examining the data collected from the designed survey, we found that people in Taiwan showed high confidence in their AI knowledge. Moreover, people showed a high level of support toward AI's capacity to improve human lives and at the same time admitted the potential that human lives could be monitored or even ruled by AI. Briefly speaking, they were highly involved in AI, with a very positive attitude and a sense of risk toward AI, similar to people in developed countries such as the US, Canada, and France in previous studies $[5,97]$. We tested people's sentimental response to AI and found that most of them thought of $\mathrm{AI}$ as convenient, admirable, hopeful, close, and worrying and dangerous simultaneously. Thus, we can conclude that people in Taiwan are "rational optimists" or "practical optimists" regarding AI.

People in Taiwan tended to agree that AI should develop, but with effective international and domestic governance. Most respondents thought AI could create as much as possible but without autonomous decision-making capacity, i.e., not self-aware like AGI. This result confirmed again that people in Taiwan wanted to develop AI with well-defined and well-managed restrictions. Moreover, they understood that private benefit is the real driving force of AI development. That is, they dealt with realism and idealism altogether like typical educated people in a democratic society with an open market economy.

This study is one of the pioneering works incorporating how people think of the linkages between AI and the SDGs. The SDGs for quality education, industry innovation, and good health had the highest support rate. In contrast, those for reducing inequality, eradicating poverty, and economic growth gained the most concern. It was also observed that people did not care about the SDGs related to gender and other inequality. These results reflected the current situation in Taiwan that people thought they lived in an equal society as universal education, the unique health care system, and good socioeconomic development offered the supporting power. Their worries about the possible negative consequences of AI development were also prominent. According to the data analysis, education played as the base for constructing a sustainable AI-aided town with an embedded innovative circular economy and high-quality water and energy services, making the residents live healthier lives. Strong correlations can be found among the three categorized AI-SDG linkages, representing a synergized point of view among the three categories of SDGs when the respondents considered AI. The findings of this study can be referred to when the perceptions of AI and sustainability issues were of interest for emerging high-tech economies such as Taiwan and other Asian countries.

The results of this study can echo the vision and context of "AI for Good" that AIrelated issues are complicated and multi-dimensional. Thus, we need to use AI to improve people's living quality and minimize the gaps between different groups at the same time. The survival and development of human beings are the ultimate objectives of all initiatives and efforts toward sustainable development. As the SDGs have become a commonly used framework to interpret sustainable development in various fields, the AI-SDG connections were shown to be applicable to indicate the critical issues of AI, i.e., the safety and dignity of humans. Cybersecurity has already been recognized as one highly prioritized source of apparent global risks by the WEF [19]. People in a newly industrialized and democratic society such as Taiwan treated transparency, ethics, and full civil participation as the key factors of successful AI governance. This finding agrees with the core values of the SDGs, diversity, inclusion, and "no one left behind".

We have tried to consider diversified viewpoints and aspects related to people's perceptions toward AI, together with AI-SDG connections. However, we also needed to limit the questionnaire length to maintain the quality of sampling. Limitations of this research also included that sampling was not employed randomly. Although we assumed that people capable of answering the AI-related questions should have internet access, the sampling bias might exist as there were still many people not connecting themselves to cyberspace for different reasons. 
Based on the results of this study, we may plan for further research with the survey questions more focused on the issues identified as critically important in this study. With more resources prepared, the sampling can be carried out systemically following the stratified random sampling standards. Furthermore, the quantitative research results can be strengthened with qualitative methodologies such as focus groups or expert interviews. Extended studies can also be planned and implemented for AI-related technology professionals to understand possible differences between their perceptions of AI and those of laypeople. How these professionals weigh AI development and sustainability in multiple aspects is also of significant interest.

In Taiwan, a new Ministry of Digital Development has been in the preparation stage for several years, aiming at digital government, information governance, industrial development, and other related tasks. The research results of this study can be good background information for the government as well as the civil society to have intense discussions concerning the balance between cybersecurity and data sovereignty and the trade-off between management efficiency and governance ethics. Diversified opinions could be observed from multiple stakeholders. Additionally, incorporating the framework and core values of the SDGs into AI governance should be emphasized in an open and democratic society.

Author Contributions: S.-C.Y. coordinated the study and wrote most of the manuscript; A.-W.W. performed the statistical analysis and edited the draft; H.-C.Y. and H.C.W. helped design the questionnaire and collect data; Y.-P.K. helped edit the manuscript; P.-X.C. helped check statistical tests. All authors have read and agreed to the published version of the manuscript.

Funding: This research was funded by the Ministry of Science and Technology, Taiwan (MOST 107-2511-H-003-049-MY3, 2018).

Institutional Review Board Statement: Ethical review and approval were waived for this study due to the random and anonymous sampling without conflicts with the respondents' rights.

Informed Consent Statement: Informed consent was shown in the first paragraph of the survey questionnaire such that the respondent understood the data would be used for academic publications.

Data Availability Statement: The data presented in this study are available on request from the corresponding author.

Acknowledgments: The authors acknowledge the valuable suggestions from each co-leader in the integrated research program. Additionally, thanks should be given to our master's and doctoral students for help distributing the web-based survey. The authors also appreciate the time and energy that reviewers offered.

Conflicts of Interest: The authors declare no conflict of interest.

\section{Appendix A}

Table A1. The survey questionnaire of this study.

\begin{tabular}{llc}
\hline \multicolumn{1}{c}{ Question } & Selection Options \\
\hline 2. & $\begin{array}{l}\text { How frequently did you use AI products or } \\
\text { services in your work or daily lives? }\end{array}$ & $\begin{array}{c}\text { always, often, occasionally, not often, } \\
\text { not at all }\end{array}$ \\
3. $\quad \begin{array}{l}\text { How frequently did you actively understand the } \\
\text { new trends of AI products or services? }\end{array}$ & $\begin{array}{c}\text { always, often, occasionally, not often, } \\
\text { not at all }\end{array}$ \\
\hline
\end{tabular}


Table A1. Cont.

\section{Question}

4. How frequently did you actively learn the way to use AI products or services?

5. To what extent do you think the following products or services are involved with AI?

(1) Social media, e.g., Facebook, Instagram

(2) Communication software, e.g., Line, WeChat

(3) Web browser, e.g., google chrome, IE

(4) Mobile payment, e.g., Line Pay, Google Pay, Apple Pay

(5) Health management, e.g., smartwatch, smart bracelet

(6) Home appliances, e.g., sweeping robot, voice-controlled light

6. Please select the item that best describes how you feel about AI-related technology

7. Please select the item that best describes how you agree with the following statements.

(1) AI products or services are easy to learn

(2) The operation guidelines of AI products or services are not easy to follow

(3) AI products or services easily break down

(4) AI products or services promote my quality of life

(5) AI products or services offer useful information

8. What do you think of the possibility of the following event or phenomenon being brought about by AI?

(1) AI improves the efficiency of human society

(2) $\mathrm{AI}$ allows people to have more time to realize their dreams

(3) AI offers solutions to complicated problems

(4) AI changes laypeople's decision-making capacity

(5) AI changes human experts' decision-making capacity

(6) AI monitors human lives

(7) AI increases the unemployment rate

(8) AI rules human beings

\section{Selection Options}

always, often, occasionally, not often, not at all

tightly involved, moderately involved, slightly involved, not involved at all

agree very much, agree, not agree, not agree at all

extremely likely, very likely, slightly likely, impossible 
Table A1. Cont.

\begin{tabular}{l} 
Question \\
\hline $\begin{array}{l}\text { Who should be most responsible for the safety } \\
\text { of AI? }\end{array}$
\end{tabular}
of AI?

10. How much do you agree that the expansion and promotion of AI products and services should only be for public interests?

11. How much do you agree that private interests drive the development of AI-related technologies?

12. How much do you agree that only with permission of the litigant should information related to AI products or services be collected?

13. How much do you agree that citizens have the right to participate in the legislative processes of AI-related laws and regulations?

14. What should be the most critical category of AI literacy for all generations?

15. How confident are you in the following statement related to "AI technologies and applications can be soundly managed"?
(1) Personal data can be well-protected
(2) Autonomous cars won't risk road safety
(3) AI will not be used for military purposes
(4) AI will not decide to eliminate human beings

16. To what extent do you think AI technology should be developed?

17. Wat do you think of the importance of the following aspects of AI management or governance?
(1) Ethics
(2) Transparency
(3) Democracy
(4) Laws and regulations

18. Do you hope for more AI products and services in your daily lives?

\section{Selection Options}

the UN, the international institute of monitoring AI technological development, the iconic AI R\&D lab, the government, the commercial company using $\mathrm{AI}$, the independent research organization, the civil society

agree very much, agree, not agree, not agree at all

agree very much, agree, not agree, not agree at all

agree very much, agree, not agree, not agree at all

agree very much, agree, not agree, not agree at all

living with $\mathrm{AI}$, working with $\mathrm{AI}$, operating AI, managing AI

extremely confident, confident, not confident, not confident at all

no AI development, simple work with basic identification intelligence, multiple tasks without autonomous decision-making capacity, multiple tasks with autonomous decision-making capacity

extremely important, important, not important, not important at all

extremely, very, fairly, slightly, not at all 
Table A1. Cont.

19. Have you ever seen this picture before this moment?

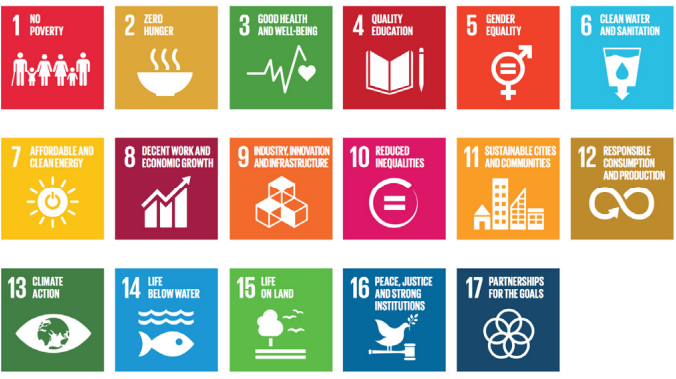

20. How do you understand the UN Sustainable Development Goals (SDGs)?

21. How do you think of the connection between AI and each of the following SDGs?

(If you think AI can promote or help the SDG, please select "positive" or "very positive" depending on your perception. Likewise, if you think AI will hinder or inhibit the SDG, please select "negative" or "very negative" as well.)

SDG 1 no poverty

SDG 2 no hunger

SDG 3 good health and well-being

SDG 4 quality education

SDG 5 gender equality

SDG 6 clean water and sanitation

SDG 7 affordable and clean energy

SDG 8 decent work and economic growth

SDG 9 industry, innovation, and infrastructure

SDG 10 reduced inequalities

SDG 11 sustainable cities and communities

SDG 12 responsible consumption and production

SDG 13 climate action

SDG 14 life below water

SDG 15 life on land

SDG 16 peace, justice, and strong institutions

SDG 17 partnerships for the goals

22. Please let us know your physical gender

23. Please let us know your birth year

24. In which kind of region do you reside now? yes, no

extremely, very, fairly, slightly, not at all

very positive, positive, negative, very negative

female, male

insert a number

urban, rural 
Table A1. Cont.

\begin{tabular}{cc}
\hline Question & Selection Options \\
\hline 25. Please let us know your education level & $\begin{array}{c}\text { junior college students, junior college } \\
\text { graduates, college students, college } \\
\text { graduates, master students, master } \\
\text { graduates, doctoral students, } \\
\text { Ph.D., others } \\
\text { 26. Please let us know your college major } \\
\\
\text { engineering, science, agriculture, } \\
\text { humanity, law, business, theology, } \\
\text { information, social sciences, } \\
\text { education, life science, art, sport, } \\
\text { hospitality and tourism, } \\
\text { communication and design, medicine } \\
\text { and health care }\end{array}$ \\
\hline
\end{tabular}

\section{References}

1. Grace, K.; Salvatier, J.; Dafoe, A.; Zhang, B.; Evans, O. When will AI exceed human performance? Evidence from AI experts. J. Artif. Intell. Res. 2018, 62, 729-754. [CrossRef]

2. Denning, P.J.; Denning, D.E. Dilemmas of artificial intelligence. Commun. ACM 2020, 63, 22-24. [CrossRef]

3. Turchin, A.; Denkenberger, D. Classification of global catastrophic risks connected with artificial intelligence. AI Soc. 2020, 35, 147-163. [CrossRef]

4. Gherhes, V.; Obrad, C. Technical and humanities students' perspectives on the development and sustainability of artificial intelligence (AI). Sustainability 2018, 10, 3066. [CrossRef]

5. Kelley, P.G.; Yang, Y.; Heldreth, C.; Moessner, C.; Sedley, A.; Kramm, A.; Newman, D.T.; Woodruff, A. Exciting, Useful, Worrying, Futuristic: Public Perception of Artificial Intelligence in 8 Countries. arXiv 2019, arXiv:2001.00081.

6. Soltau, F. Automation and artificial intelligence-what could it mean for sustainable development? U. N. Dep. Econ. Soc. Aff. 2016. Available online: https://sustainabledevelopment.un.org/content/documents/968825_Soltau_Automation\%20and\%20 artificial\%20intelligence $\% 20-\% 20$ what $\% 20$ could \%20it\%20mean\%20for\%20sustainable\%20development.pdf (accessed on 20 June 2021).

7. Sharma, G.D.; Yadav, A.; Chopra, R. Artificial intelligence and effective governance: A review, critique and research agenda. Sustain. Futures 2020, 2, 100004. [CrossRef]

8. McCarthy, J. Artificial intelligence, logic and formalizing common sense. In Philosophical Logic and Artificial Intelligence; Springer: Dordrecht, The Netherlands, 1989; pp. 161-190.

9. Gurkaynak, G.; Yilmaz, I.; Haksever, G. Stifling artificial intelligence: Human perils. Comput. Law Secur. Rev. 2016, 32, 749-758. [CrossRef]

10. Soviany, C. The benefits of using artificial intelligence in payment fraud detection: A case study. J. Paym. Strategy Syst. 2018, 12, 102-110.

11. Floridi, L.; Cowls, J.; Beltrametti, M.; Chatila, R.; Chazerand, P.; Dignum, V.; Luetge, C.; Madelin, R.; Pagallo, U.; Rossi, F.; et al. AI4People-An ethical framework for a good AI society: Opportunities, risks, principles, and recommendations. Minds Mach. 2018, 28, 689-707. [CrossRef]

12. Vinuesa, R.; Azizpour, H.; Leite, I.; Balaam, M.; Dignum, V.; Domisch, S.; Tegmark, M.; Nerini, F. The role of artificial intelligence in achieving the Sustainable Development Goals. Nat. Commun. 2020, 11, 1-10. [CrossRef]

13. Russell, S.; Bohannon, J. Artificial intelligence. Fears of an AI pioneer. Science 2015, 349, 252.

14. Bostrom, N.; Cirkovic, M.M. (Eds.) Global Catastrophic Risks; Oxford University Press: Oxford, UK, 2011.

15. Yudkowsky, E. Artificial intelligence as a positive and negative factor in global risk. Glob. Catastrophic Risks 2008, 1, 184.

16. Lorenc, T. Artificial Intelligence and the Ethics of Human Extinction. J. Conscious. Stud. 2015, 22, $194-214$.

17. Wilson, E.O. The Future of Life; Vintage: New York, NY, USA, 2002.

18. Russell, S. Human Compatible: Artificial Intelligence and the Problem of Control; Viking: New York, NY, USA, 2019.

19. WEF. The Global Risks Report 2020; Insight Report; WEF: Colony, Switzerland, 2020.

20. MIT Technology Review Insights Archive Page, Asia's AI Agenda: The Ethics of AI. 2019. Available online: https://www. technologyreview.com/2019/07/11/134229/asias-ai-agenda-the-ethics-of-ai/ (accessed on 20 June 2021).

21. Gill, K.S. Data Driven Wave of Certainty-a question of ethical sustainability. IFAC-PapersOnLine 2016, 49, 117-122. [CrossRef]

22. Floridi, L. Soft ethics, the governance of the digital and the General Data Protection Regulation. Philos. Trans. R. Soc. A Math. Phys. Eng. Sci. 2018, 376, 2133.

23. Timmers, P. Ethics of AI and cybersecurity when sovereignty is at stake. Minds Mach. 2019, 29, 635-645. [CrossRef]

24. Montes, G.A.; Goertzel, B. Distributed, decentralized, and democratized artificial intelligence. Technol. Forecast. Soc. Chang. 2019, 141, 354-358. [CrossRef] 
25. Marinakis, V.; Koutsellis, T.; Nikas, A.; Doukas, H. AI and Data Democratisation for Intelligent Energy Management. Energies 2021, 14, 4341. [CrossRef]

26. Singi, K.; Choudhury, S.G.; Kaulgud, V.; Bose, R.J.C.; Podder, S.; Burden, A.P. Data Sovereignty Governance Framework. In Proceedings of the IEEE/ACM 42nd International Conference on Software Engineering Workshops, Seoul, Korea, 27-19 June 2020; pp. 303-306.

27. Dabrock, P. How to Put the Data Subject's Sovereignty into Practice. Ethical Considerations and Governance Perspectives. In Proceedings of the AAAI/ACM Conference on AI, Ethics, and Society, New York, NY, USA, 7-8 February 2020; pp. 1-2.

28. Jarke, M.; Otto, B.; Ram, S. Data Sovereignty and Data Space Ecosystems. Bus. Inf. Syst. Eng. 2019, 61, 549-550. [CrossRef]

29. Dafoe, A. Global Politics and the Governance of Artificial Intelligence. J. Int. Aff. 2018, 72, 121-126.

30. UNEDSA. SDG Implementation in the UN Systems: International Telecommunication Union (ITU). Available online: https: / / sdgs.un.org/un-system-sdg-implementation/international-telecommunication-union-itu-24522 (accessed on 5 June 2021).

31. Mikhaylov, S.J.; Esteve, M.; Campion, A. Averill. Artificial intelligence for the public sector: Opportunities and challenges of cross-sector collaboration. Philos. Trans. R. Soc. A Math. Phys. Eng. Sci. 2018, 376, 20170357. [CrossRef]

32. Hager, G.D.; Drobnis, A.; Fang, F.; Ghani, R.; Greenwald, A.; Lyons, T.; Parkes, D.C.; Schultz, J.; Saria, S.; Tambe, M.; et al. Artificial intelligence for social good. arXiv 2019, arXiv:1901.05406.

33. Chui, M.; Harryson, M.; Manyika, J.; Roberts, R.; Chung, R.; van Heteren, A.; Nel, P. Applying AI for Social Good; Discussion Paper; McKinsey \& Company, 2018; Available online: https: / www.mckinsey.com/featured-insights/artificial-intelligence/applyingartificial-intelligence-for-social-good\# (accessed on 20 June 2021).

34. Schneegans, S. Artificial Intelligence for Sustainable Development: Challenges and Opportunities for UNESCO's Science and Engineering Programmes. 2019. Available online: https:/ / unesdoc.unesco.org/ark:/48223/pf0000368028 (accessed on 20 June 2021).

35. Chakroun, B.; Miao, F.; Mendes, V.; Domiter, A.; Fan, H.; Kharkova, I.; Holmes, W.; Orr, D.; Jermol, M.; Issroff, K.; et al. Artificial Intelligence for Sustainable Development: Synthesis Report, Mobile Learning Week 2019. 2019. Available online: https:/ /iite.unesco.org/publications/ai-for-sustainable-development-synthesis-report/ (accessed on 20 June 2021).

36. Khakurel, J.; Penzenstadler, B.; Porras, J.; Knutas, A.; Zhang, W. The rise of artificial intelligence under the lens of sustainability. Technologies 2018, 6, 100. [CrossRef]

37. Zhang, H.; Song, M.; He, H. Achieving the success of sustainability development projects through big data analytics and artificial intelligence capability. Sustainability 2020, 12, 949. [CrossRef]

38. Yun, J.J.; Lee, D.; Ahn, H.; Park, K.; Yigitcanlar, T. Not deep learning but autonomous learning of open innovation for sustainable artificial intelligence. Sustainability 2016, 8, 797. [CrossRef]

39. How, M.L.; Cheah, S.M.; Chan, Y.J.; Khor, A.C.; Say, E.M.P. Artificial intelligence-enhanced decision support for informing global sustainable development: A human-centric Ai-Thinking approach. Information 2020, 11, 39. [CrossRef]

40. Davenport, T.; Guha, A.; Grewal, D.; Bressgott, T. How artificial intelligence will change the future of marketing. J. Acad. Mark. Sci. 2020, 48, 24-42. [CrossRef]

41. Mosteanu, N.R. International Financial Markets face to face with Artificial Intelligence and Digital Era. Theor. Appl. Econ. 2019, $26,123-134$.

42. Overgoor, G.; Chica, M.; Rand, W.; Weishampel, A. Letting the computers take over: Using AI to solve marketing problems. Calif. Manag. Rev. 2019, 61, 156-185. [CrossRef]

43. UNESCO. Beijing Consensus on Artificial Intelligence (AI) and Education. 2019. Available online: https://unesdoc.unesco.org/ ark:/48223/pf0000368303 (accessed on 20 June 2021).

44. UNESCO. Final Report Planning Education in the Al Era: Lead the Leap. 2019. Available online: https://en.unesco.org/themes/ ict-education/ai-education-conference-2019 (accessed on 20 June 2021).

45. McCalla, G. The fragmentation of culture, learning, teaching and technology: Implications for the artificial intelligence in education research agenda in 2010. Int. J. Artif. Intell. Educ. 2000, 11, 177-196.

46. Ikedinachi, A.P.; Misra, S.; Assibong, P.A.; Olu-Owolabi, E.F.; Maskeliūnas, R.; Damasevicius, R. Artificial intelligence, smart classrooms and online education in the 21st century: Implications for human development. J. Cases Inf. Technol. (JCIT) 2019, 21, 66-79. [CrossRef]

47. SDG. Knowledge Platforms, Objectives and Themes of Rio+20. Available online: https://sustainabledevelopment.un.org/rio20/ objectivethemes (accessed on 17 May 2021).

48. Frank, M.R.; Autor, D.; Bessen, J.E.; Brynjolfsson, E.; Cebrian, M.; Deming, D.J.; Feldman, M.; Groh, M.; Lobo, J.; Moro, E.; et al. Toward understanding the impact of artificial intelligence on labor. Proc. Natl. Acad. Sci. USA 2019, 116, 6531-6539. [CrossRef]

49. George, B.; Paul, J. Digital Transformation in Business and Society; Springer International Publishing: New York, NY, USA, 2020.

50. Vochozka, M.; Kliestik, T.; Kliestikova, J.; Sion, G. Participating in a highly automated society: How artificial intelligence disrupts the job market. Econ. Manag. Financ. Mark. 2018, 13, 57-62.

51. Tambe, P.; Cappelli, P.; Yakubovich, V. Artificial intelligence in human resources management: Challenges and a path forward. Calif. Manag. Rev. 2019, 61, 15-42. [CrossRef]

52. Makridakis, S. The forthcoming Artificial Intelligence (AI) revolution: Its impact on society and firms. Futures 2017, 90, 46-60. [CrossRef] 
53. Jarrahi, M.H. Artificial intelligence and the future of work: Human-AI symbiosis in organizational decision making. Bus. Horiz. 2018, 61, 577-586. [CrossRef]

54. Brougham, D.; Haar, J. Smart technology, artificial intelligence, robotics, and algorithms (STARA): Employees' perceptions of our future workplace. J. Manag. Organ. 2018, 24, 239-257. [CrossRef]

55. Panch, T.; Pearson-Stuttard, J.; Greaves, F.; Atun, R. Artificial intelligence: Opportunities and risks for public health. Lancet Digit. Health 2019, 1, e13-e14. [CrossRef]

56. Panch, T.; Szolovits, P.; Atun, R. Artificial intelligence, machine learning and health systems. J. Glob. Health $2018,8,020303$. [CrossRef]

57. Wahl, B.; Cossy-Gantner, A.; Germann, S.; Schwalbe, N.R. Artificial intelligence (AI) and global health: How can AI contribute to health in resource-poor settings? BMJ Glob. Health 2018, 3, e000798. [CrossRef] [PubMed]

58. Garbuio, M.; Lin, N. Artificial intelligence as a growth engine for health care startups: Emerging business models. Calif. Manag. Rev. 2019, 61, 59-83. [CrossRef]

59. Allam, Z.; Jones, D.S. On the coronavirus (COVID-19) outbreak and the smart city network: Universal data sharing standards coupled with artificial intelligence (AI) to benefit urban health monitoring and management. Multidiscip. Digit. Publ. Inst. 2020, 8, 46. [CrossRef] [PubMed]

60. Pirouz, B.; Shaffiee Haghshenas, S.; Shaffiee Haghshenas, S.; Piro, P. Investigating a serious challenge in the sustainable development process: Analysis of confirmed cases of COVID-19 (new type of coronavirus) through a binary classification using artificial intelligence and regression analysis. Sustainability 2020, 12, 2427. [CrossRef]

61. McCall, B. COVID-19 and artificial intelligence: Protecting health-care workers and curbing the spread. Lancet Digit. Health 2020, 2, e166-e167. [CrossRef]

62. Bragazzi, N.L.; Dai, H.; Damiani, G.; Behzadifar, M.; Martini, M.; Wu, J. How big data and artificial intelligence can help better manage the COVID-19 pandemic. Int. J. Environ. Res. Public Health 2020, 17, 3176. [CrossRef] [PubMed]

63. Shaffiee Haghshenas, S.; Pirouz, B.; Shaffiee Haghshenas, S.; Pirouz, B.; Piro, P.; Na, K.S.; Cho, S.E.; Geem, Z.W. Prioritizing and analyzing the role of climate and urban parameters in the confirmed cases of COVID-19 based on artificial intelligence applications. Int. J. Environ. Res. Public Health 2020, 17, 3730. [CrossRef]

64. Popa, C. Adoption of artificial intelligence in agriculture. Bull. Univ. Agric. Sci. Vet. Med. Cluj-Napoca. Agric. 2011, 68, $284-293$.

65. Jha, K.; Doshi, A.; Patel, P.; Shah, M. A comprehensive review on automation in agriculture using artificial intelligence. Artif. Intell. Agric. 2019, 2, 1-12. [CrossRef]

66. Quinn, J.; Frias-Martinez, V.; Subramanian, L. Computational sustainability and artificial intelligence in the developing world. AI Mag. 2014, 35, 36-47. [CrossRef]

67. De Silva, L.C.; Morikawa, C.; Petra, I.M. State of the art of smart homes. Eng. Appl. Artif. Intell. 2012, 25, 1313-1321. [CrossRef]

68. Adio-Moses, D.; Asaolu, O.S. Artificial intelligence for sustainable development of intelligent buildings. In Proceedings of the 9th CIDB Postgraduate Conference, at University of Cape Town, Cape Town, South Africa, 2-4 February 2016.

69. Jha, S.K.; Bilalovic, J.; Jha, A.; Patel, N.; Zhang, H. Renewable energy: Present research and future scope of Artificial Intelligence. Renew. Sustain. Energy Rev. 2017, 77, 297-317. [CrossRef]

70. Allam, Z.; Dhunny, Z.A. On big data, artificial intelligence and smart cities. Cities 2019, 89, 80-91. [CrossRef]

71. Chui, K.T.; Lytras, M.D.; Visvizi, A. Energy sustainability in smart cities: Artificial intelligence, smart monitoring, and optimization of energy consumption. Energies 2018, 11, 2869. [CrossRef]

72. Lytras, M.D.; Chui, K.T. The recent development of artificial intelligence for smart and sustainable energy systems and applications. Energies 2019, 12, 3108. [CrossRef]

73. Şerban, A.C.; Lytras, M.D. Artificial intelligence for smart renewable energy sector in Europe-Smart energy infrastructures for next generation smart cities. IEEE Access 2020, 8, 77364-77377. [CrossRef]

74. Cook, D.J.; Das, S.K. How smart are our environments? An updated look at the state of the art. Pervasive Mob. Comput. 2007, 3, 53-73. [CrossRef]

75. Bugmann, G.; Siegel, M.; Burcin, R. A role for robotics in sustainable development? In Proceedings of the IEEE Africon'11, Victoria Falls, Zambia, 13-15 September 2011; pp. 1-4.

76. Fung, K.F.; Huang, Y.F.; Koo, C.H.; Mirzaei, M. Improved SVR machine learning models for agricultural drought prediction at downstream of Langat River Basin, Malaysia. J. Water Clim. Chang. 2020, 11, 1383-1398. [CrossRef]

77. Chia, M.Y.; Huang, Y.F.; Koo, C.H. Support vector machine enhanced empirical reference evapotranspiration estimation with limited meteorological parameters. Comput. Electron. Agric. 2020, 175, 105577. [CrossRef]

78. Chia, M.Y.; Huang, Y.F.; Koo, C.H.; Fung, K.F. Recent advances in evapotranspiration estimation using artificial intelligence approaches with a focus on hybridization techniques-A review. Agronomy 2020, 10, 101. [CrossRef]

79. Jain, P.; Deo, M.C. Artificial intelligence tools to forecast ocean waves in real time. Open Ocean Eng. J. 2008, 1, 13-20. [CrossRef]

80. Issaka, Y.; Kumi-Boateng, B. Artificial intelligence techniques for predicting tidal effects based on geographic locations in Ghana. Geod. Cartogr. 2020, 46, 1-7. [CrossRef]

81. Sathiya, V.; Chinnadurai, M.; Ramabalan, S.; Appolloni, A. Mobile robots and evolutionary optimization algorithms for green supply chain management in a used-car resale company. Environ. Dev. Sustain. 2021, 23, 9110-9138. [CrossRef]

82. Yeh, S.C.; Chiou, H.J.; Wu, A.W.; Lee, H.C.; Wu, H.C. Diverged preferences towards sustainable development goals? A comparison between academia and the communication industry. Int. J. Environ. Res. Public Health 2019, 16, 4577. [CrossRef] 
83. UN Department of Global Communication. We Can End Poverty: MDGs and Beyond 2015. Available online: https://www.un. org/millenniumgoals / (accessed on 10 July 2021).

84. United Nations. Transforming Our World: The 2030 Agenda for Sustainable Development. Available online: https: / / sustainabledevelopment.un.org/content/documents/21252030\%20Agenda\%20for\%20Sustainable\%20Development $\% 20$ web.pdf (accessed on 10 December 2015).

85. Tremblay, D.; Fortier, F.; Boucher, J.F.; Riffon, O.; Villeneuve, C. Sustainable development goal interactions: An analysis based on the five pillars of the 2030 agenda. Sustain. Dev. 2020, 28, 1584-1596. [CrossRef]

86. Szennay, Á.; Szigeti, C.; Kovács, N.; Szabó, D.R. Through the blurry looking glass-SDGs in the GRI reports. Resources 2019, 8, 101. [CrossRef]

87. ElAlfy, A.; Palaschuk, N.; El-Bassiouny, D.; Wilson, J.; Weber, O. Scoping the evolution of corporate social responsibility (CSR) research in the sustainable development goals (SDGs) era. Sustainability 2020, 12, 5544. [CrossRef]

88. Cole, M.J.; Broadhurst, J.L. Mapping and classification of mining host communities: A case study of South Africa. Extr. Ind. Soc. 2020, 7, 954-964. [CrossRef]

89. Khoshnava, S.M.; Rostami, R.; Zin, R.M.; Štreimikienė, D.; Yousefpour, A.; Strielkowski, W.; Mardani, A. Aligning the criteria of green economy (GE) and sustainable development goals (SDGs) to implement sustainable development. Sustainability 2019, 11, 4615. [CrossRef]

90. Saner, R.; Yiu, L.; Nguyen, M. Monitoring the SDGs: Digital and social technologies to ensure citizen participation, inclusiveness and transparency. Dev. Policy Rev. 2020, 38, 483-500. [CrossRef]

91. Le Blanc, D. Towards integration at last? The sustainable development goals as a network of targets. Sustain. Dev. 2015, 23, 176-187. [CrossRef]

92. Pradhan, P.; Costa, L.; Rybski, D.; Lucht, W.; Kropp, J.P. A systematic study of sustainable development goal (SDG) interactions. Earth's Future 2017, 5, 1169-1179. [CrossRef]

93. Nilsson, M.; Griggs, D.; Visbeck, M. Policy: Map the interactions between Sustainable Development Goals. Nat. News 2016, 534, 320. [CrossRef] [PubMed]

94. Sachs, J.D. From Millennium Development Goals to Sustainable Development Goals. Lancet 2012, 379, 2206-2211. [CrossRef]

95. Mathiyazhagan, K.; Agarwal, V.; Appolloni, A.; Saikouk, T.; Gnanavelbabu, A. Integrating lean and agile practices for achieving global sustainability goals in Indian manufacturing industries. Technol. Forecast. Soc. Chang. 2021, 171, 120982. [CrossRef]

96. ITU. WSIS-SDG Matrix Linking WSIS Action Lines with Sustainable Development Goals. 2015. Available online: https: //www.itu.int/net4/wsis/sdg/ (accessed on 20 June 2021).

97. Sadowski, M.; Powell-Tuck, R. AI the Sustainable Development Goals: The State of Play. 2017. Available online: https: //www.sustainability.com/thinking/ai-and-the-sustainable-development-goals-the-state-of-play/ (accessed on 20 June 2021).

98. Truby, J. Governing Artificial Intelligence to benefit the UN Sustainable Development Goals. Sustain. Dev. 2020, 28, 946-959. [CrossRef]

99. Fast, E.; Horvitz, E. Long-term trends in the public perception of artificial intelligence. In Proceedings of the AAAI Conference on Artificial Intelligence, San Francisco, CA, USA, 4-9 February 2017.

100. Zhai, Y.; Yan, J.; Zhang, H.; Lu, W. Tracing the evolution of AI: Conceptualization of artificial intelligence in mass media discourse. Inf. Discov. Deliv. 2020, 48, 137-149. [CrossRef]

101. Ouchchy, L.; Coin, A.; Dubljević, V. AI in the headlines: The portrayal of the ethical issues of artificial intelligence in the media. AI Soc. 2020, 35, 927-936. [CrossRef]

102. Chuan, C.H.; Tsai, W.H.S.; Cho, S.Y. Framing artificial intelligence in American newspapers. In Proceedings of the 2019 AAAI/ACM Conference on AI, Ethics, and Society, Honolulu, HI, USA, 27-28 January 2019; pp. 339-344.

103. Gao, S.; He, L.; Chen, Y.; Li, D.; Lai, K. Public perception of artificial intelligence in medical care: Content analysis of social media. J. Med. Internet Res. 2020, 22, e16649. [CrossRef]

104. Neri, H.; Cozman, F. The role of experts in the public perception of risk of artificial intelligence. AI Soc. 2019, 35, 663-673. [CrossRef]

105. European Commission, Attitudes towards the Impact of Digitisation and Automation on Daily Life. 2017. Available online: https:/ / europa.eu/ eurobarometer/surveys/detail/2160 (accessed on 6 June 2021).

106. Lozano, I.A.; Molina, J.M.; Gijón, C. Perception of Artificial Intelligence in Spain. Telemat. Inform. 2021, 63, 101672. [CrossRef]

107. Wang, X. Using sentiment analysis for comparing attitudes between computer professionals and laypersons on the topic of artificial intelligence. In Proceedings of the 2019 3rd International Conference on Natural Language Processing and Information Retrieval, Tokushima, Japan, 28-29 June 2019; pp. 5-8.

108. Joppa, L.; Herweijer, C. How AI Can Enable a Sustainable Future-PwC; 2019. Available online: https://www.pwc.co.uk/ sustainability-climate-change/assets/pdf/how-ai-can-enable-a-sustainable-future.pdf (accessed on 20 June 2021).

109. Byer, B. What Do Consumers Think about Artificial Intelligence? Smart Brief. Available online: https://www.smartbrief.com/ original/2020/04/what-do-consumers-think-about-artificial-intelligence (accessed on 17 May 2021).

110. Mozilla. We Asked People around the World How They Feel about Artificial Intelligence. Here's What We Learned. 2019. Available online: https:/ / foundation.mozilla.org/en/blog/we-asked-people-around-the-world-how-they-feel-about-artificialintelligence-heres-what-we-learned/ (accessed on 20 June 2021). 
111. Lee, Y.; Kozar, K.A.; Larsen, K.R. The technology acceptance model: Past, present, and future. Commun. Assoc. Inf. Syst. 2003, 12, 50. [CrossRef]

112. Barbier, E.B.; Burgess, J.C. The Sustainable Development Goals and the systems approach to sustainability. Econ. Open-Access E-J. 2017, 11, 1-23. [CrossRef]

113. Ajani, T.; Stork, E. Creating a Semantic Differential Scale for measuring users' perceptions and attitudes toward emerging technologies. In Proceedings of the Conference for Information Systems Applied Research ISSN, San Antonio, TX, USA, 7-10 November 2013; pp. 1508-2167.

114. Akalin, N.; Kiselev, A.; Kristoffersson, A.; Loutfi, A. An evaluation tool of the effect of robots in eldercare on the sense of safety and security. In International Conference on Social Robotics; Springer: Cham, Switzerland, 2017; pp. 628-637.

115. Zeng, Y.; Lu, E.; Huangfu, C. Linking artificial intelligence principles. arXiv 2018, arXiv:1812.04814.

116. Müller, V.C. (Ed.) Risks of Artificial Intelligence; CRC Press: Boca Raton, FL, USA, 2016.

117. BBC. Available online: https:/ / www.bbc.com/ukchina/trad/50236993 (accessed on 5 May 2021).

118. Bhatti, A.; Saad, S.; Gbadebo, S.M. Convenience risk, product risk, and perceived risk influence on online shopping: Moderating effect of attitude. Int. J. Bus. Manag. 2018, 3, 1-11.

119. Ali, S.; Ali, S.F.; Imam, A.M.; Ayub, S.; Billoo, A.G. Perception and practices of breastfeeding of infants 0-6 months in an urban and a semi-urban community in Pakistan: A cross-sectional study. J. Pak. Med. Assoc. 2011, 61, 99.

120. Amin, M.; Yahya, Z.; Ismayatim, W.F.A.; Nasharuddin, S.Z.; Kassim, E. Service quality dimension and customer satisfaction: An empirical study in the Malaysian hotel industry. Serv. Mark. Q. 2013, 34, 115-125. [CrossRef]

121. Dos Santos, D.P.; Giese, D.; Brodehl, S.; Chon, S.H.; Staab, W.; Kleinert, R.; Baeßler, B. Medical students' attitude towards artificial intelligence: A multicentre survey. Eur. Radiol. 2019, 29, 1640-1646. [CrossRef]

122. Goswami, A.; Dutta, S. Gender differences in technology usage-A literature review. Open J. Bus. Manag. 2015, 4, 51-59. [CrossRef]

123. Liaw, S.S.; Huang, H.M. A study of investigating learners' attitudes toward e-learning. In Proceedings of the 5th International Conference on Distance Learning and Education, Rome, Italy, 21-23 July 2011; Volume 12, pp. $28-32$.

124. Araujo, T.; Helberger, N.; Kruikemeier, S.; De Vreese, C.H. In AI we trust? Perceptions about automated decision-making by artificial intelligence. AI Soc. 2020, 35, 611-623. [CrossRef]

125. Folke, C.; Biggs, A.V.R.; Norström, B.R.; Rockström, J. Social-ecological resilience and biosphere-based sustainability science. Ecol. Soc. 2016, 21, 41. [CrossRef]

126. University of Wisconsin. Country Health Rankings and Roadmaps. Available online: https://www.countyhealthrankings. org/explore-health-rankings/measures-data-sources / county-health-rankings-model/health-factors/social-and-economicfactorsn (accessed on 20 June 2021).

127. World Economic Forum. Global Social Mobility Index 2020: Why Economies Benefit from Fixing Inequality. Available online: https:/ / www.weforum.org/reports/global-social-mobility-index-2020-why-economies-benefit-from-fixing-inequality (accessed on 19 June 2021).

128. Appolloni, A.; D'Adamo, I.; Gastaldi, M.; Santibanez-Gonzalez, E.D.; Settembre-Blundo, D. Growing e-waste management risk awareness points toward new recycling scenarios: The view of the Big Four's youngest consultants. Environ. Technol. Innov. 2021, 23, 101716. [CrossRef] 